\title{
Review of Fiber Optic Sensors for Structural Fire Engineering
}

\author{
Yi Bao ${ }^{1}$, Ying Huang ${ }^{2}$, Matthew S. Hoehler ${ }^{3}\left(\mathbb{D}\right.$ and Genda Chen ${ }^{4, *}$ (i) \\ 1 Department of Civil, Environmental and Ocean Engineering, Stevens Institute of Technology, 1 Castle Point \\ Terrace, Hoboken, NJ 07030, USA; yi.bao@stevens.edu \\ 2 Department of Civil and Environmental Engineering, North Dakota State University, Fargo, ND 58105, USA; \\ ying.huang@ndsu.edu \\ 3 National Fire Research Laboratory, National Institute of Standards and Technology, Gaithersburg, MD 20899, \\ USA; matthew.hoehler@nist.gov \\ 4 Department of Civil, Architectural and Environmental Engineering, Missouri University of Science and \\ Technology, Rolla, MO 65409, USA \\ * Correspondence: gchen@mst.edu
}

Received: 27 January 2019; Accepted: 17 February 2019; Published: 20 February 2019

\begin{abstract}
Reliable and accurate measurements of temperature and strain in structures subjected to fire can be difficult to obtain using traditional sensing technologies based on electrical signals. Fiber optic sensors, which are based on light signals, solve many of the problems of monitoring structures in high temperature environments; however, they present their own challenges. This paper, which is intended for structural engineers new to fiber optic sensors, reviews various fiber optic sensors that have been used to make measurements in structure fires, including the sensing principles, fabrication, key characteristics, and recently-reported applications. Three categories of fiber optic sensors are reviewed: Grating-based sensors, interferometer sensors, and distributed sensors.
\end{abstract}

Keywords: fiber optic sensors; high temperature; intelligent sensors; smart structure; structural fire engineering

\section{Introduction}

Fire can cause structural damage with catastrophic consequences. The strength and stability of structures can be significantly impacted by the adverse effects of temperature-induced deformations and degraded material properties at elevated temperatures [1-4]. In a structure fire, room gas temperatures from $600{ }^{\circ} \mathrm{C}$ to $1200^{\circ} \mathrm{C}$ are common [5]. Concrete begins to lose significant strength when the material temperature exceeds $350{ }^{\circ} \mathrm{C}$ and ceases to be structurally useful for temperatures more than $550{ }^{\circ} \mathrm{C}$ [6]. Structural steels are commonly considered to have lost half of their room temperature yield strength around $540{ }^{\circ} \mathrm{C}$ [7] and have lost the majority of their strength above $700{ }^{\circ} \mathrm{C}$. To assess the thermo-mechanical conditions of a structure during or after a fire, temperatures and strains are critical $[8,9]$. However, the extreme environmental and material temperatures, as well as large transient temperature variations present in a fire, make monitoring of temperatures and strains challenging.

Traditional measurement tools for structural fire engineering include thermocouples for temperature measurement, strain gauges for local deformation measurement, and displacement transducers for the measurement of global displacements [10]. These sensors, which utilize electrical signals, typically have a limited operating temperature range and can be susceptible to electromagnetic interference. Furthermore, they provide measurements only at a single point. Because the properties in a structure often vary across the physical scale of interest, multiple data points are necessary to adequately characterize the property. Consequently, a great number of sensors must be deployed 
to obtain measurements at multiple locations; which involves cumbersome wiring of the sensors in large specimens.

In recent years, fiber optic sensors have drawn interest for the monitoring of structures in fire environments due to their unique characteristics such as immunity to electromagnetic interference (EMI), compact size, and stability in harsh environments [11]. These advantages motivate this review, which aims to inspire further advancement of fiber optic sensor technology and to provide guidance for the selection and use of fiber optic sensors for structural fire applications.

The paper provides a brief introduction intended for structural fire engineers of the basic concepts of fiber optic sensors and then describes the three primary types of fiber optic sensors that have been applied in structural fire applications in more detail. For each sensor type, the paper reviews the sensing principle, fabrication, key characteristics, and recent structural fire applications. In addition to the fiber optic sensors that have been applied in structural fire engineering, some sensors that are promising for this application, but have not been applied in fires, are also discussed. While interesting studies on sapphire optical fibers have been conducted in recent years [12,13], application of sapphire-based optical fibers in structural fire engineering remains rare. This review focuses on fiber optic sensors made of fused silica fibers.

\section{Basic Concepts of Fiber Optic Sensors}

Fiber optic sensors function based on measuring the characteristics of light transmitted along an optical fiber. Changes in the fiber caused by external actions, for example, changes in the temperature or stress state of the fiber, resulting in variations in the transmitted light signal that can be calibrated to the measurand. Different fiber optic sensor types utilize different physical phenomena to modulate the transmitted light; which gives each sensor its characteristic performance. Relevant functional principles for this review are discussed in the following sections. For a general discussion of fiber optic sensors, a wealth of literature is available [14-17].

Optical fibers can be categorized into single-mode fibers (SMFs) and multi-mode fibers (MMFs) according to the number of waveguide modes in the fiber. Typically, SMFs consists of a fiber core ( $8 \mu \mathrm{m}$ to $10 \mu \mathrm{m}$ in diameter), a cladding $(\approx 125 \mu \mathrm{m}$ in diameter), and one or more layers of protective coating, as illustrated in Figure 1a. For fused silica fibers, the fiber core and cladding are made of high-purity fused silica, doped with germanium to increase the refractive index; although other dopants may be used. Light waves are transmitted along the fiber through total internal reflection at the core-cladding interface as illustrated in Figure 1b. Multi-mode fibers have a larger diameter core that allows multiple propagation modes of the guided wave (Figure 1b). Compared with MMFs, SMFs have higher transmission speed and lower transmission loss, and thus generally more suitable for long-distance applications.

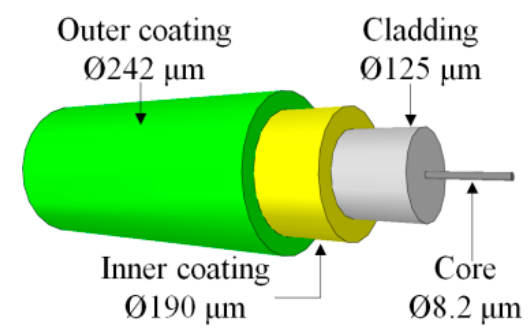

(a)

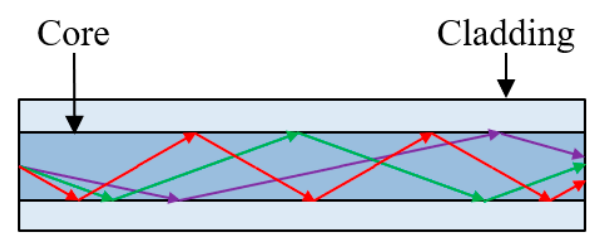

(b)

Figure 1. Optical fiber: (a) Typical cross section; (b) waveguide principle.

Three categories of fiber optic sensors have been reported in the context of structural fire engineering: Grating sensors, interferometer sensors, and distributed sensors [18]. Grating sensors and interferometer sensors are referred to as "point sensors" because they only measure at the locations where a grating or interface is present. Some point sensors can be multiplexed to form 
a quasi-distributed sensor for measurements at multiple locations [19]. Distributed fiber optic sensors provide measurements at multiple points along the optical fiber.

\section{Grating Sensors}

Optical fiber gratings are made by periodic perturbation of the refractive index along a length of optical fiber. The phase-matching condition of gratings can be described by Equation (1) [20]:

$$
\beta_{1}-\beta_{2}=\Delta \beta=2 \pi / \Lambda
$$

where $\Lambda$ represents the period of the grating; $\beta_{1}$ and $\beta_{2}$ are the propagation constants of the coupled modes, and $\Delta \beta$ is the difference between the two propagation constants. Depending on the period length, fiber gratings can be classified into fiber Bragg gratings (FBGs) and long-period fiber gratings (LPFGs). In an FBG, the forward-propagating fundamental mode $\left(\mathrm{LP}_{01}, \beta_{1}=\beta_{01}\right)$ couples to the reverse-propagating fundamental mode $\left(\beta_{2}=-\beta_{01}<0\right)$, resulting in a large $\Delta \beta$ and a period that is typically less than $1 \mu \mathrm{m}$. LPFG couples the fundamental mode to forward-propagating cladding modes $\left(\beta_{2}>0\right)$, resulting in periods that are typically greater than $100 \mu \mathrm{m}$. The longer period leads to a longer grating length, which results in a longer sensor length and less precise sensing location.

\subsection{Fiber Bragg Grating Sensors}

\subsubsection{Principle}

In an FBG sensor, a narrow band of the incident optical field within the fiber is reflected by successive, coherent scattering from the index variations, as illustrated in Figure 2. The strongest interaction, or mode coupling, occurs at the Bragg wavelength [21], as described by Equation (2):

$$
\lambda_{B}=2 n_{e f f} \Lambda_{B}
$$

where $\lambda_{B}, n_{\text {eff }}$, and $\Lambda_{B}$ represent the Bragg wavelength, the effective refractive index of the fiber core, and the period of the grating, respectively.

The effective refractive index of the fiber core and the period of grating, $n_{e f f}$ and $\Lambda_{B}$, vary with the fiber temperature and strain. In a structural fire testing, the temperature and strain of the sensor can be determined by measuring the central wavelength shift of the FBG, provided the temperature and strain sensitivity coefficients that are calibrated before the testing. The effects of temperature and strain on the fiber can be decoupled by measuring the temperature separately using a second sensor for temperature compensation.

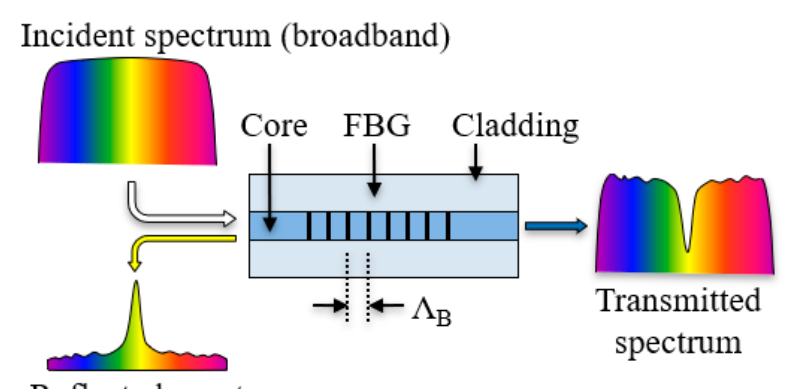

Reflected spectrum

Figure 2. Illustration of reflection of fiber Bragg gratings (FBG).

\subsubsection{Fabrication and Key Characteristics}

FBGs are typically about $5 \mathrm{~mm}$ in length and fabricated using a phase-mask approach to obtain gratings with controlled spectral response [22]. To generate phase-mask gratings, a laser is focused on the fiber core through a phase mask that causes an interference pattern and inscribes multiple 
points. This requires the fiber core to be photosensitive. Another method to fabricate gratings is the point-by-point writing approach; where the fiber core is inscribed one point at a time using a laser. Point-by-point writing is inefficient for gratings with many index perturbations, such as FBGs; however, it is often appropriate for making LPFGs.

Traditionally, FBGs have been divided into two categories based on the formation mechanisms: Type I and Type II [23]. Conventional Type I gratings are formed through a single ultraviolet (UV) photon absorption process that excites oxygen deficiency centers in the fiber core [24]. At elevated temperatures, Type I gratings degrade as a result of the thermal depopulation of trapped excited states that are created during the grating formation, because atoms at excited state can absorb energy and return to the ground state. Therefore, Type I gratings are typically not applicable for measurements over $400{ }^{\circ} \mathrm{C}$. The refractive index change of Type I FBGs is almost completely annealed at temperatures over $600{ }^{\circ} \mathrm{C}$. Type II gratings use high-power pulsed UV laser sources to locally damage the fiber core or the core-cladding interface for the formation of periodic perturbation on refractive index [25]. Type II gratings in fused silica fiber have been used for temperature measurements higher than $1000{ }^{\circ} \mathrm{C}$ [26]. Therefore, the fabrication technique significantly influences the performance of the gratings and must be considered when selecting FBG sensors for structural fire applications. Furthermore, the stability and uncertainty of the measure must be considered for the range of application conditions.

Regenerated FBGs (RFBGs) fabricated through a hydrogen loading process are reported in [27-29]. A hydrogen loading process requires an optical fiber to be exposed to high pressure hydrogen gas at room temperature until saturated with hydrogen that permeates the glass matrix. The fiber is then exposed to UV irradiation that results in the formation of highly reflective seed gratings, which are then completely or partially removed in a thermal annealing process [23]. Further heating at high temperature regenerates gratings, which have smooth spectra and are stable at temperatures above $1000{ }^{\circ} \mathrm{C}[30,31]$.

\subsubsection{Structural Fire Applications}

FBG sensors have been applied to measure gas temperature in a scaled (1:20) tunnel [11], and the measurements were compared with measurements from type- $\mathrm{K}$ thermocouples and theoretical (predicted) temperatures. The maximum operating temperature of the FBG sensors was $350{ }^{\circ} \mathrm{C}$. The FBG sensors were attached to a bundle of wires suspended in the tunnel, with no additional protection, as shown in Figure 3a. During the fire test, the FBG sensors measured temperatures up to $300{ }^{\circ} \mathrm{C}$. Compared with the theoretical temperatures, the authors show that the results from the FBG sensors were more accurate than the measurement from the uncorrected thermocouples, which were subjected to radiation-induced temperature reduction. In the study [11], potential strain effect on the measurement from the FBG sensors was not considered, although the ventilation-induced air flow might impact the strain and thus center wavelength in the FBG sensors.

As discussed in the introduction, gas temperatures higher than $350{ }^{\circ} \mathrm{C}$ can be expected in a fire environment. With a regenerated FBG, temperature measurements up to $1295^{\circ} \mathrm{C}$ were demonstrated using a microheater [32]. Bueno et al. [33] tested three types of FBGs embedded in concrete cylinders under fire. The three types were (1) FBG inscribed in photosensitive germanium-boron co-doped fiber, (2) regenerated FBG inscribed in germanium doped fiber, and (3) regenerated FBG in germanium-boron co-doped fiber. The FBG sensors were embedded in the concrete cylinders without additional protection and a survival rate of $92 \%$. The concrete cylinders were placed in a furnace where the temperature was increased above $1000{ }^{\circ} \mathrm{C}$, following the standard ISO 834 fire curve [34]. The testing was continued for $120 \mathrm{~min}$. The temperatures measured from the FBGs were compared with the temperatures measured from type-K thermocouples. While the ordinary FBGs were annealed (and ceased to measure) at $420{ }^{\circ} \mathrm{C}$, the measurement from the regenerated FBGs agreed with the measurement from thermocouples above $1000{ }^{\circ} \mathrm{C}$, demonstrating the viability of the regenerated FBGs at these temperatures. 
Following the above study, the same research group conducted more fire testing of concrete beams using the regenerated FBG [35,36]. Rinaudo et al. [35] installed regenerated FBG sensors, which were packaged for mechanical and fire protection, on the surface of concrete beams using a metallic composite adhesive (Figure 3b), which retains an adequate bond with concrete at up to $1093{ }^{\circ} \mathrm{C}$. The authors claimed that the regenerated FBGs measured the gas temperature, although the FBGs were encased in the package. Type-K thermocouples were closely installed on the concrete beams to measure gas temperature for comparison. Two concrete beams were tested in a furnace for one hour, following the standard ISO 834 fire curve [34]. The regenerated FBGs measured temperatures up to $990{ }^{\circ} \mathrm{C}$ and showed agreement with the measurement from the type-K thermocouples. Torres Górriz et al. [36] embedded the packaged regenerated FBGs in a reinforced concrete beam subjected to elevated temperatures, as shown in Figure 3c. To protect the sensors and transmission cable, they were passed through a flexible PVC tube, which was attached to the steel bars for mechanical protection during concrete casting and might decompose as the temperature exceeded $120^{\circ} \mathrm{C}$. Type-K thermocouples were used to measure temperature for comparison. The beam was tested in a fire for $77 \mathrm{~min}$, following the standard ISO 834 fire curve. The temperature measured by the regenerated FBGs was up to $953^{\circ} \mathrm{C}$, and overall in agreement with the measurement from the thermocouples. The authors learned that the transmission cable of the fiber optic sensor should be carefully protected throughout the sensor installation, specimen fabrication, and fire testing.

Advantages of FGB sensors for structural fire applications include: (1) Lower cost electronics (measurement system) compared to other fiber optic technologies, (2) good sensor reliability, and robustness due to the high sensitivity to temperature and insensitivity to other environmental variables such as refractive index, and (3) ease of sensor packaging and installation due to the short sensor length. A primary drawback is that FGB gratings are annealed (erased) at temperatures too low for most applications in the fire. While this drawback can be overcome using regenerated gratings, the fabrication process is cumbersome and the resulting gratings have low reflectivity, which limits their ability to be multiplexed.

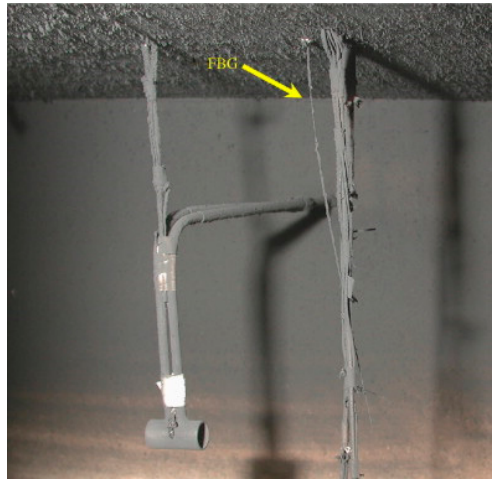

(a)

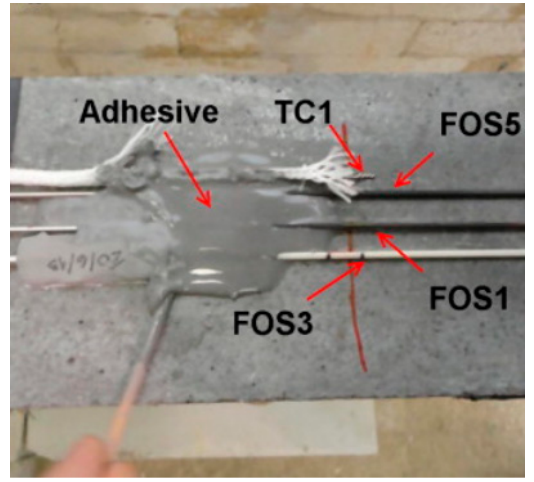

(b)

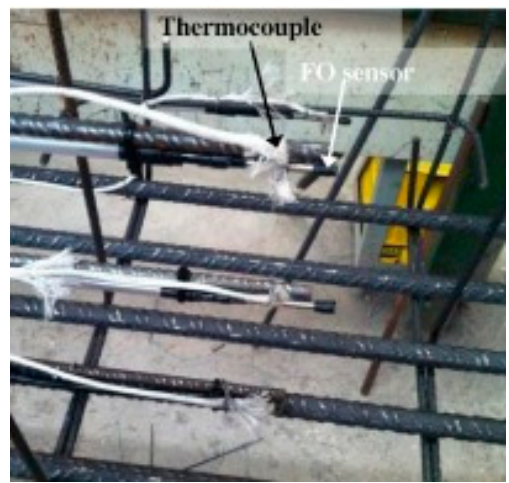

(c)

Figure 3. Application of FBG sensors in structural fire testing: (a) Gas temperature [11],

(b) surface-attached on concrete beams [35], and (c) embedded in reinforced concrete beams [36].

\subsubsection{Other Promising FBG Technologies}

Micro-fabrication techniques using femtosecond lasers have been exploited to inscribe FBGs in optical fibers without the requirement of photosensitivity of the fiber core [37,38]. Both Type I and Type II gratings have been inscribed using femtosecond lasers and a phase mask [39]. During the microfabrication process, an optical fiber absorbs energy from the femtosecond laser through nonlinear phenomena such as multiphoton, tunneling, and avalanche ionization. The absorbed energy locally damages the fiber, which leads to the formation of void-like grating structures [38]. FBGs fabricated in fused silica fibers using femtosecond lasers can provide stable temperature or strain measurements at an elevated temperature of $1000^{\circ} \mathrm{C}$ for about $400 \mathrm{~h}$, but a permanent drift of the central wavelength 
was observed at $1050^{\circ} \mathrm{C}$ [40]. Thermal annealing at high temperature has been used to enhance the thermal stability of FBGs fabricated using femtosecond lasers [41]. After pre-annealing at $1100{ }^{\circ} \mathrm{C}$, the FBGs demonstrated sustained reflectivity up to $1200^{\circ} \mathrm{C}$ for more than $20 \mathrm{~h}$ [41]. Despite the great potential, the microfabricated FBGs have not been applied in structural fire testing, likely due to the fabrication cost, thus their feasibility must be further verified.

The upper operating temperature of FBGs is limited by the softening point and thermal degradation of the fiber material, such as de-vitrification. The softening point of silica fibers is between $1200{ }^{\circ} \mathrm{C}$ and $1600{ }^{\circ} \mathrm{C}$ depending on the type and content of additive materials. Single crystal sapphire has a melting point around $2050{ }^{\circ} \mathrm{C}$ and thus might possibly increase the temperature limit. FBGs inscribed in sapphire fibers have been reported for measurements up to $1850{ }^{\circ} \mathrm{C}$ [12-14]. Femtosecond lasers were used to fabricate the FBGs in sapphire fibers since they provided high peak intensities and multi-photon processes to permanently change the refractive index. However, sapphire fibers do not have fiber cladding and are multimode fibers, which involve more significant signal loss and require more complex interrogators. Light waves are constrained by the interface between the fiber core and the environment, and thus, the light waves are sensitive to the environmental conditions and surface defects. Such sensitivity must be considered in structural fire applications, since other environmental variables and surface conditions may affect the measurement.

\subsection{Long Period Fiber Grating Sensors}

\subsubsection{Principle, Fabrication, and Key Characteristics}

There are two waveguide interfaces in an optical fiber with a long-period fiber grating (LPFG): (1) The core surrounded by a cladding, and (2) the cladding surrounded by the environment (e.g., air). Phase matching of the guided core mode and a forward-propagating cladding mode of an LPFG occurs at the resonance wavelength $\lambda$, which is described in Equation (3) [42]:

$$
\lambda=\left[n_{e f f}(\lambda)-n_{\text {clad }}^{i}(\lambda)\right] \Lambda
$$

where $n_{\text {eff }}(\lambda)$ is the effective refractive index of the propagating core mode at the wavelength $\lambda, n_{\text {clad }}^{i}(\lambda)$ is the refractive index of the $\mathrm{i}^{\text {th }}$ cladding mode, and $\Lambda$ is the period of the grating.

The high attenuation of the LPFG cladding modes results in a series of attenuation bands in the transmission spectrum of the fiber at discrete resonant wavelengths; each attenuation band corresponds to the coupling to a different cladding mode [42]. The resonant wavelengths of the attenuation bands are sensitive to the period of the LPFG and the effective refractive index with influences from the local environment: Temperature, bending radius, and the refractive index of the surrounding medium [43]. Typically, a higher order of coupling mode corresponds to a greater resonant wavelength and larger intensity of transmission loss. As temperature or strain changes, the resonant wavelengths are shifted, and the shifted quantity of resonant wavelength can be measured to calibrate the temperature and strain sensitivity of the LPFGs.

The period of LPFGs is in the range from $100 \mu \mathrm{m}$ to $1 \mathrm{~mm}$, and the length is in the order of $30 \mathrm{~mm}$. Similar to FBG, the phase mask technique and point-by-point writing technique can be used to fabricate LPFGs [42]. While the phase mask and UV exposure method are widely used for fabricating FBGs, the point-by-point writing technique is more convenient to use for LPFG fabrication because of the relatively large periodicity. In addition to UV irradiation, $\mathrm{CO}_{2}$ laser [44], femtosecond laser [45], and electric arc fabrication [46] have also been used to fabricate gratings. In a photonic crystal fiber, LPFGs were fabricated by periodically collapsing the holes of the fiber using a $\mathrm{CO}_{2}$ laser [47]. LPFGs fabricated by $\mathrm{CO}_{2}$ laser irradiation are reported to be stable up to $1200{ }^{\circ} \mathrm{C}$ [44]. Femtosecond lasers were used to fabricate LPFGs based on densification of the glass, and the LPFG allowed for measurements at temperatures up to $500{ }^{\circ} \mathrm{C}$ [45]. Electric arc fabrication of an LPFG relies upon a combination of several different mechanisms to generate the periodic property modulation of 
the fiber. The mechanisms include the induction of microbend into the fiber [48], the periodic tapering of the fiber [49], the diffusion of dopants [50], ion implantation [51], and the relaxation of internal stresses [52]. The operating temperature range of such LPFGs has been demonstrated to be up to $800{ }^{\circ} \mathrm{C}$ without permanent modification of their properties [53], and, if annealed they may operate at temperatures up to $1190^{\circ} \mathrm{C}[46]$.

\subsubsection{Structural Fire Applications}

Recently, an LPFG sensor was inscribed in a fused silica SMF using a $\mathrm{CO}_{2}$ laser and deployed for high temperature and large strain measurement [54]. Although the fused silica fiber with LPFGs is fragile and prone to fracture under mechanical loading, an innovative mechanism for scaling down the thermal elongation was designed to delay the strain increase and protect the LPFG from a fracture at high temperature. The LPFG sensors inscribed using the $\mathrm{CO}_{2}$ laser were operated at temperatures up to $700{ }^{\circ} \mathrm{C}$.

Following the same concept, the LPFG sensor was improved and used to measure temperatures up to $800^{\circ} \mathrm{C}$, as elaborated in reference [55]. Then, the LPFG sensors were applied in a large-scale steel frame for temperature measurement in a simulated fire environment (Figure 4). One of the columns was partially exposed to the fire effect to investigate the thermomechanical behavior of a steel frame under the fire [56]. A two-part ceramic adhesive that can endure temperatures up to $1100{ }^{\circ} \mathrm{C}$ was used to attach the LPFG sensors to the inside surfaces of the column flanges. The sensor data were used for real-time updating of a finite element model to accurately predict the thermomechanical responses of the steel frame under a fire. The LPFG sensors measured temperatures up to $800{ }^{\circ} \mathrm{C}$.
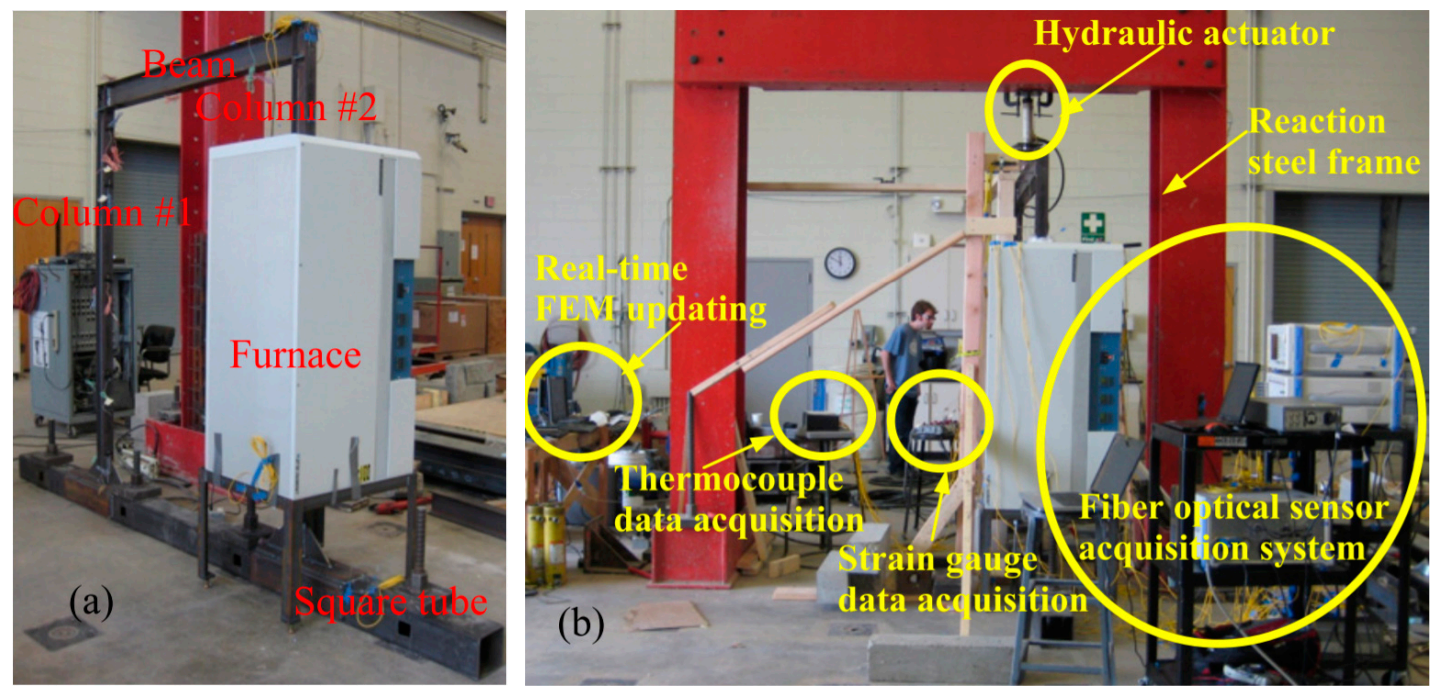

Figure 4. Application of long-period fiber gratings (LPFG) sensors in structural fire [56]: (a) Test set-up, and (b) instrumentation.

Compared with FBG sensors, the application of LPFG sensors in structural fire research is relatively new. Although the fabrication of LPFGs is straightforward and cost-effective, LPFGs are sensitive to bending of the optical fiber and refractive index of the environment, implying that more attention must be paid to the sensor installation and data interpretation. For a successful structural fire application, the LPFGs must be properly packaged to minimize undesired bending and environmental influences on the refractive index and to enhance the mechanical strength and ruggedness of the sensor. However, the sensitivity to bending and refractive index offers opportunities to develop multifunctional LPFG sensors, for example, to measure refractive index, rotation due to bending, and temperature simultaneously, although the feasibility remains unclear. 


\section{In-line Interferometer Sensors}

A fiber optic interferometer uses the interference between two coherent light beams traveling along different paths to measure the variables that alter the interference pattern. Four types of fiber optic interferometers have been demonstrated: Fabry-Perot interferometers (FPIs), Mach-Zehnder interferometers (MZIs), Michelson interferometers (MIs), and Sagnac interferometers (SIs). An FPI is formed by light reflected from two parallel surfaces at discontinuities along the beam paths. For MZIs, MIs, and SIs, the interference is normally generated by splitting an incident light into two paths using a fiber splitter followed by recombining them using a fiber combiner. Early MZIs, MIs, and SIs had two arms, and thus had disadvantages such as complicated structure, large size, and high susceptibility to environmental changes. Recently, various in-line fiber optic core-cladding-mode interferometers (CCMI) have been developed to replace the two-arm structures. The CCMI operates on the interference between the core and the cladding modes in a single optical fiber. In structural fire applications, different interferometer sensors are suited to measuring temperature or strains.

\subsection{In-line Fabry-Perot Interferometer Sensors}

\subsubsection{Principle}

Interference occurs when a reflected light and a transmitted light are coherent at two reflecting surfaces (R1 and R2 in Figure 5). The reflection spectrum of an FPI can be described as the wavelength dependent intensity modulation of the input light spectrum [57], which is mainly caused by the optical phase difference between two reflected light beams. Constructive interference occurs if the reflected beams are in phase, and this corresponds to a high-reflection peak. If the reflected beams are out-of-phase, destructive interference occurs and this corresponds to a reflection minimum. Whether the reflected beams are in phase depends on the wavelength $(\lambda)$ of the incident light (in vacuum), the angle $(\theta)$ with which the incident light travels through the reflecting surfaces, the length $(L)$ between the reflecting surfaces, and the refractive index $(n)$ of the material between the reflecting surfaces. The phase difference between each reflected pair of an FPI is given as [58]:

$$
\phi=\frac{2 \pi}{\lambda} 2 n L \cos (\theta)
$$

When any perturbation is introduced to an FPI, the phase difference is influenced by the variation in the optical path distance of the interferometer [59]. For example, applying a longitudinal strain to an FPI sensor changes $L$, which in turn results in phase variation. By measuring the shift of the wavelength, the applied strain can be quantified.

A number of techniques have been reported to form FPIs, such as thin film deposition [60,61], forming a micro-notch using femtosecond lasers [62], offset structures [63], chemical etching [64,65], and splicing [66]. Depending on the physical structure of an FPI, in-line FPIs can be categorized into extrinsic FPI (EFPI) and intrinsic FPI (IFPI). As illustrated in Figure 5, an EFPI has a cavity between the reflecting surfaces (R1 and R2), while an IFPI does not have the cavity.

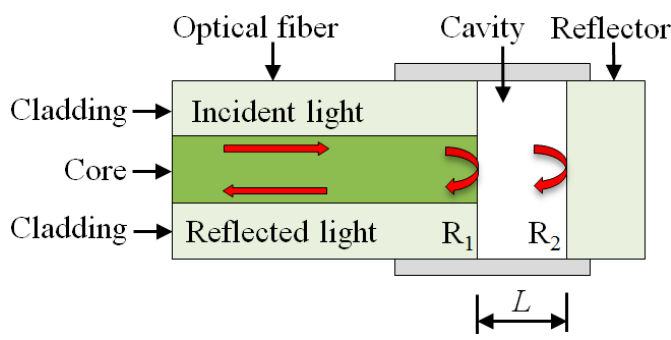

(a)

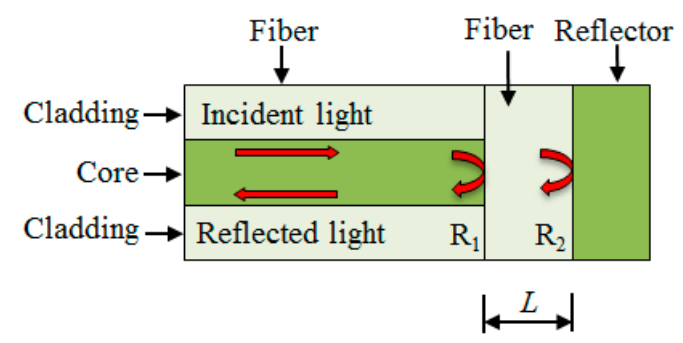

(b)

Figure 5. Illustration of Fabry-Perot Interferometers (FPIs): (a) Extrinsic (E)FPI; (b) intrinsic (I)FPI. 


\subsubsection{Structural Fire Applications and Key Characteristics}

Due to the discontinuity of the optical fiber at the cavity, the physical strain limitation of the optical fiber, and thus, EFPIs can be used to measure large strains. The reflector can be a cleaved end of an optical fiber or a mirror with a high reflectivity (Figure 5a). The use of a mirror helps minimize the size of the sensor, facilitating sensor installation in structures. Customized EFPIs have been used to measure the strain of steel plates in a fire [67], as shown in Figure 6. The steel plate measured $10 \mathrm{~mm}$ in thickness and was simply supported on two steel pipes with a span length of $1.42 \mathrm{~m}$. According to temperature sensors in the testing [67], both the gas temperature and the temperature in the steel plate were above $1000{ }^{\circ} \mathrm{C}$. Under gravity, creeping occurred at elevated temperatures and the steel plate exhibited a large deformation (Figure 6). The EFPI sensors were installed on the surface of the steel plate through a mechanical mechanism. The EFPI sensors were assembled using silica tubes and a two-part ceramic adhesive and installed using steel clamps and rings that were fixed on the steel plate with drilled holes. The EFPI sensors measured the reflection spectrum at temperatures above $1000^{\circ} \mathrm{C}$, and the spectrum was used to determine the strain change in the steel plate.

EFPI sensors have also been used to measure strain and crack opening in ceramic materials subjected to coal fire [68]. Crack opening widths in a range of $17 \mu \mathrm{m}$ to $33 \mu \mathrm{m}$ were measured using EFPI sensors at temperatures up to $900^{\circ} \mathrm{C}$. EFPI sensors with a similar scheme have been used to measure strains of steel frames [56]. The sensors attached on the surface of the steel columns measure large strains up to $10 \%$ at temperatures up to $800{ }^{\circ} \mathrm{C}$.

Primary disadvantages of EFPIs include low coupling efficiency, and they require careful alignment of the reflectors. The installation of these sensors can be slow and challenging, and attention must be paid to the sensor packaging [59]. Another problem for EFPI sensors with un-sealed cavities learned from live fire experiments, is that exposed reflecting surfaces can become contaminated by soot.

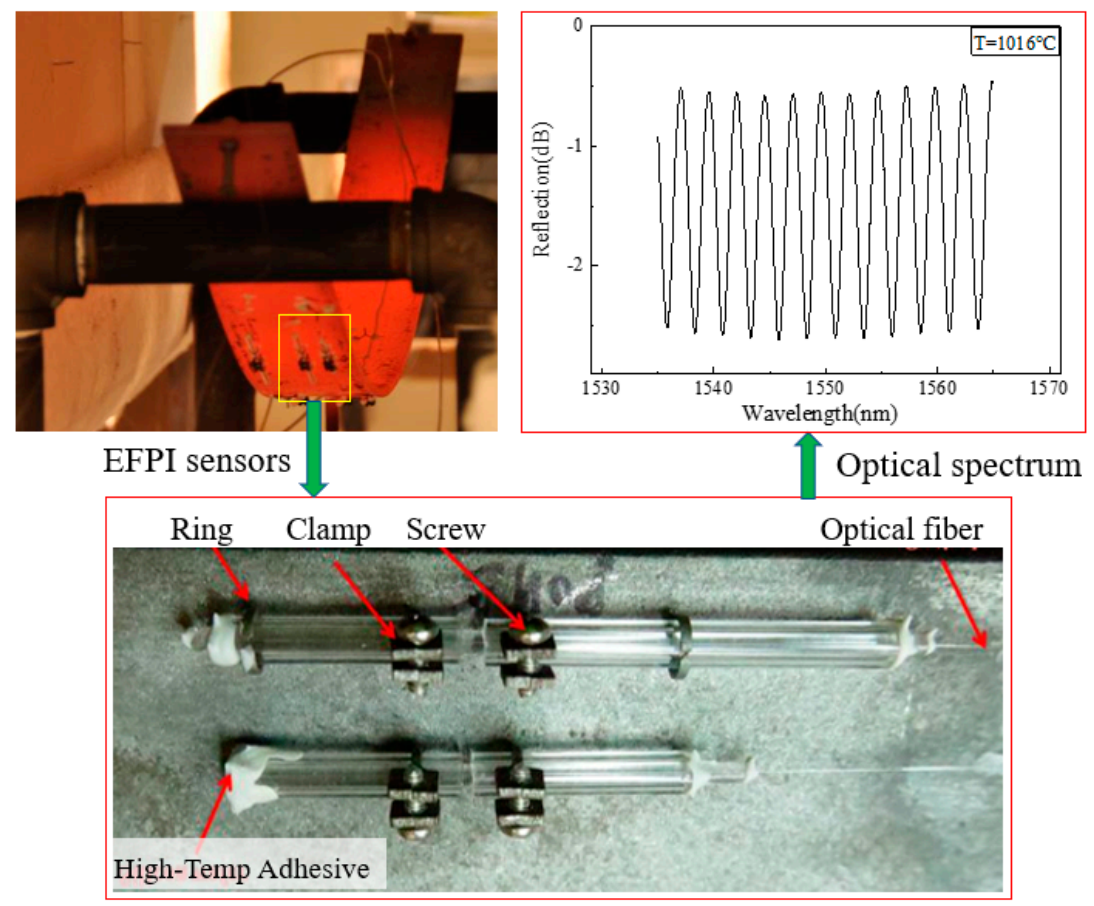

Figure 6. Application of EFPI for large strain measurement in a fire experiment of steel plates.

For IFPI, the sensing element is a short fiber sandwiched between two reflecting surfaces. The light waves of an IFPI propagate in the fiber core only, achieving higher signal intensities with a better signal demodulation compared with the EFPIs. An IFPI sensor was fabricated by creating an internal mirror in the fiber by depositing a thin layer $(\approx 100 \mathrm{~nm})$ of $\mathrm{TiO}_{2}$, which had an operation temperature up to $1050{ }^{\circ} \mathrm{C}$ [60]. Following the same concept, an IFPI with a thin layer of $\mathrm{Cr}$ operated at $1100{ }^{\circ} \mathrm{C}$ with a 
stability of $10^{\circ} \mathrm{C}$ for a duration of more than $300 \mathrm{~h}$ [61]. Micro-machining using a femtosecond laser was used to fabricate miniature IFPIs operated at temperatures up to $1100{ }^{\circ} \mathrm{C}$ [62]. An easy-to-fabricate IFPI has been presented by splicing two sections of two fibers with a large lateral offset $(\approx 62.5 \mu \mathrm{m})$ and allows for strain measurements at temperatures up to $1000{ }^{\circ} \mathrm{C}$ [63]. Recently, photonic crystal fibers (PCFs) have attracted interest because of their unique waveguide mechanisms and modal properties. A section of PCF can be spliced to a single mode fiber to form an IFPI that can operate at temperatures up to $1200{ }^{\circ} \mathrm{C}$ [69]. Miniature IFPIs with a micro air bubble can be formed by splicing PCF to a single mode fiber [70-72] to work at temperatures up to $1000{ }^{\circ} \mathrm{C}$ [73]. Sapphire fibers have been used to fabricate IFPIs that can measure temperatures exceeding $1000^{\circ} \mathrm{C}[74,75]$.

Despite the above technology advancement, IFPIs have not been applied to structural fire engineering. Compared with the EFPIs, an IFPI typically requires expensive equipment, special fibers, or toxic chemicals to fabricate the reflecting surfaces. Another reason is that the IFPIs are relatively new, and need further research to standardize the fabrication procedure and verify the performance in structural fire applications. Finally, the optical fiber of an IFPI must be continuous, which limits the strain measurement capability. However, compared with grating sensors, IFPIs have higher thermal stability, because the cavities generally are more thermally stable than the gratings, although the regenerated FBG may be very thermally stable, as indicated in reference [32].

\subsection{In-Line Fiber Optic Core-Cladding-Mode Interferometers}

\subsubsection{Principle}

In-line CCMIs require a splitting and re-coupling mechanism between the core and cladding modes, which are guided by the core-cladding and cladding-ambient interfaces, respectively. The differential phase of the core and cladding modes allows CCMIs to sense numerous environmental parameters. CCMI sensors have been demonstrated to form MZIs and MIs, as illustrated in Figure 7a,b, respectively. Both structures involve a reference arm and a sensing arm. The main difference between MZIs and MIs is that an MZI requires two couplers, while an MI only needs one coupler that splits and re-combines the two beams due to the use of mirrors in the reference and sensing arms. MZI and MI sensors measure the transmitted signals and reflected signals, respectively.

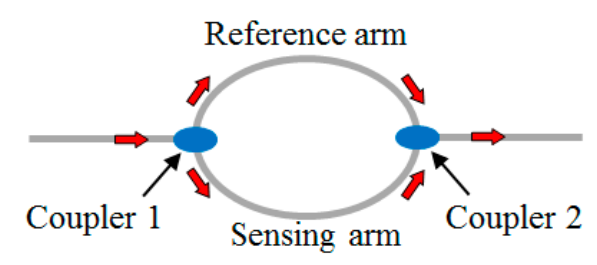

(a)

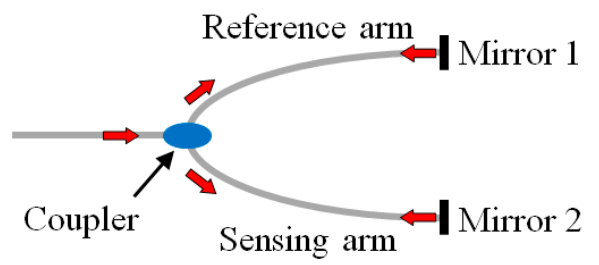

(b)

Figure 7. Illustration of Core-Cladding-Mode Interferometers (CCMIs): (a) Mach-Zehnder interferometer; (b) Michelson interferometer.

In an MZI, a beam splitter partially couples the core mode to the cladding modes and a combiner recombines the cladding modes to the core mode. The phase difference of the core and cladding modes can be described as:

$$
\Phi_{M Z I}=\frac{2 \pi\left[n_{e f f}(\lambda)-n_{\text {clad }}^{i}(\lambda)\right] L}{\lambda}
$$

where $n_{\text {eff }}(\lambda)$ is the effective refractive index of the propagating core mode, $n_{\text {clad }}^{i}(\lambda)$ is the refractive index of the $\mathrm{i}^{\text {th }}$ cladding mode, and $L$ is the fiber length between the splitter and the combiner. 
In an MI, each beam is reflected at the end of each fiber arm. The phase difference of the core and cladding modes can be described as:

$$
\Phi_{M I}=\frac{4 \pi\left[n_{e f f}(\lambda)-n_{\text {clad }}^{i}(\lambda)\right] L}{\lambda}
$$

\subsubsection{Fabrication}

Based on the principle, different innovative strategies have been presented to realize the CCMIs. A pair of LPFGs can be used as the splitters/combiners to form an MZI, as illustrated in Figure 8a [76]. The operating temperature of the MZI is therefore limited by the temperature stability and other limitations of LPFGs aforementioned. Another method to couple the core mode to cladding modes is to splice two fibers with a small lateral offset, as depicted in Figure 8b. The number of coupled cladding modes can be controlled by adjusting the amount of offset. Using fibers with different core sizes is an alternative to split the beam in a fiber as shown in Figure 8c,d. In Figure 8c, a short multimode fiber is spliced to a conventional SMF at two points [77,78]. In Figure 8d, a length of fiber with a smaller core is spliced in between two conventional single mode fibers [79]. Collapsing air holes of a PCF is another way of making an in-line MZI, as shown in Figure 8e [80]. Cavities in the fiber can also be formed using a femtosecond laser as seen in Figure 8f,g to create the splitters/combiner pairs [81,82]. Finally, tapering of the fiber can also be used to create an MZI as shown in Figure 8h [83,84]. The tapering increases the core mode diameter.

(a)

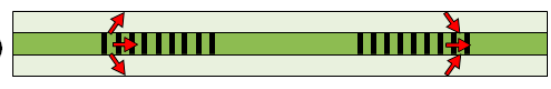

(b)

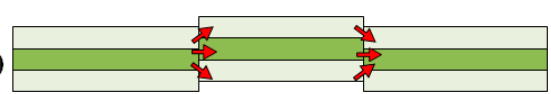

(c)

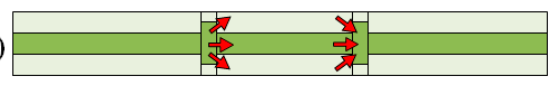

(d)

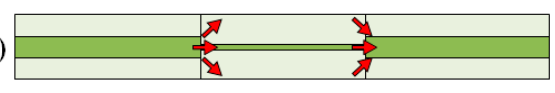

(e)

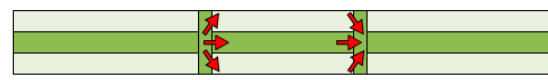

(f)

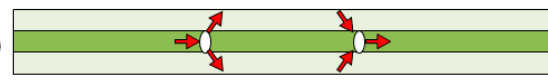

(g)

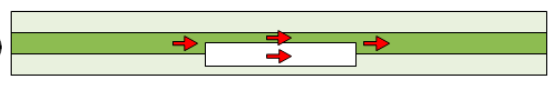

(h)

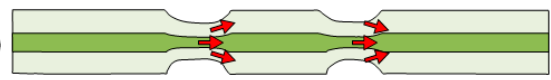

Figure 8. Configurations for in-line Mach-Zehnder interferometers: (a) A pair of LPFGs; (b) core-offset; (c) core diameter mismatch with larger core fiber; (d) core diameter mismatch with smaller core fiber; (e) air-hole collapsing of PCF; (f) cavities formed in core by femtosecond laser; (g) cavity formed at core-cladding interface by femtosecond laser; (h) fiber tapering.

The structure of an MI works as half of an MZI, as illustrated in Figure 9a,c [85,86]. The fabrication methods and the operation principle of MIs are similar to MZIs. Since MIs use reflection modes, they are more compact than MZIs. A fiber taper MI sensor was fabricated in a single more fiber by a fiber-taper machine and electric-arc discharge [86-88].

(a)

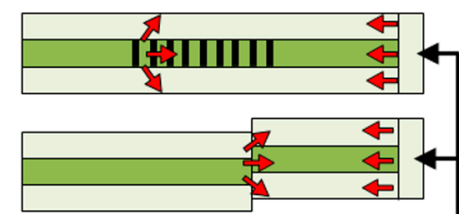

(c)

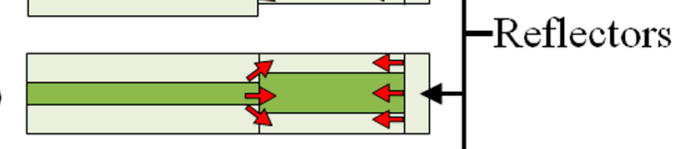

(d)

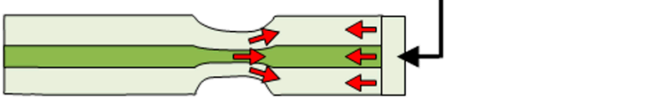

Figure 9. Example configurations for in-line Michelson interferometers: (a) Long-period fiber grating; (b) core-offset; (c) core diameter mismatch; (d) fiber tapering. 


\subsubsection{Structural Fire Applications}

Except for the designs involving LPFGs (Figures 8a and 9a), which depend on the thermal degradation of the LPFGs, the CCMIs reviewed have potential operation temperatures greater than $1000{ }^{\circ} \mathrm{C}$. For instance, research has demonstrated that the core mismatch scheme (Figures $8 \mathrm{~b}$ and $9 \mathrm{~b}$ ) does not degrade until the intrinsic degradation of the optical fiber [79,81,82,89]. The MZI formed by splicing a smaller core is spliced in between two conventional single mode fibers operated at temperatures up $1000{ }^{\circ} \mathrm{C}$ [79]. The MZIs based on cavities fabricated using a femtosecond laser operated at temperatures up to $1200^{\circ} \mathrm{C}[81,82]$. The fiber taper MI sensor fabricated by a fiber-taper machine and electric-arc discharge was used to measure the temperature at up to $1000{ }^{\circ} \mathrm{C}$ [89].

To the author's knowledge, CCMI sensors have not been used in structural fire applications. While many innovative schemes have been proposed to realize the CCMIs, further research is needed to understand their performance in fires.

\section{Distributed Fiber Optic Sensors}

In addition to transmitting signals from point sensors (e.g., grating sensors and interferometers), optical fibers can be used as distributed fiber optic sensors based on light scatterings [90], i.e., with no inscribed grating or reflection surface. The absence of gratings or reflection surfaces makes this approach attractive for high-temperature applications. Moreover, thousands of sensing points can be achieved in a single fiber. Distributed fiber optic sensors have attracted interest outside of the field of structural fire research due to the low cost of the sensor (a telecommunication-grade single-mode fiber that costs a few cents per meter serves as a sensor) and its fully-distributed sensing ability. However, the data analyzers are currently relatively expensive compared to grating sensor systems.

When light propagates through an optical fiber, it interacts with the atoms (or molecules) in the fiber, generating scattering signals that can be used to perform sensing [18]. There are three types of scattering: Rayleigh, Raman, and Brillouin scatterings, as illustrated in Figure 10. Rayleigh scattering results from the interaction between light waves and tiny particles inherent in the fiber. It is an elastic scattering process that does not involve a frequency change. Unlike Rayleigh scattering, Raman and Brillouin scattering involve frequency changes. Brillouin scattering is obtained by the interactions between light waves and acoustic waves, and Raman scattering is introduced by the interactions between light waves and molecular vibrations. Various distributed fiber optic sensing technologies have been developed based on these scattering phenomena [18]. When assessing the technologies for a particular application, one must consider tradeoffs between accuracy, spatial resolution, temporal resolution, and system cost.

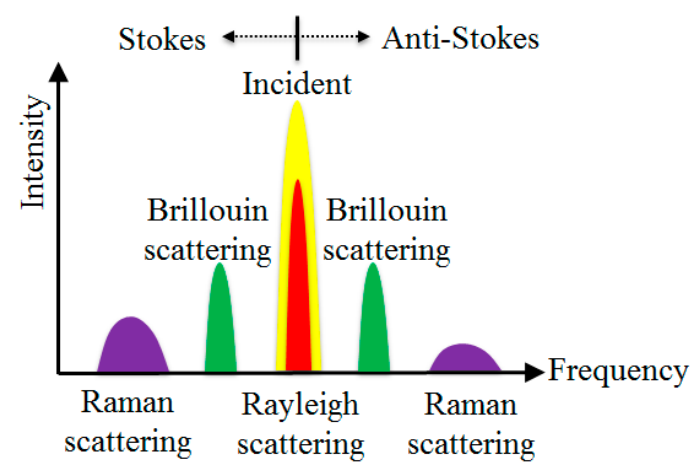

Figure 10. Light scatterings in optical fiber.

\subsection{Rayleigh Scattering Based Sensing Technologies}

The intensity of Rayleigh backscattering is mapped along the length of an optical fiber using optical time domain reflectometry (OTDR). Coherent OTDR has been developed by mixing the backscattered and reference light with a coherent detection technique [91]. Because the distances 
between scattering centers (i.e., inclusions in the fiber) are smaller than the wavelength of light, the secondary light waves from Rayleigh scattering are coherent. Rayleigh OTDR has been applied to measure temperature, strain, and displacement [92-95]. The spatial resolution is related to the signal pulse width and thus the bandwidth of the detector, electrical amplifier, and digitizer. Millimeter-scale spatial resolution, which is often required for structural applications, requires a bandwidth in the order of tens of $\mathrm{GHz}$, which necessitates a sophisticated (and often expensive) acquisition system [18]. Alternatively, optical frequency domain reflectometry (OFDR) converts the frequency response to the time domain using Fourier transforms thus that the spatial resolution with OFDR does not depend on the bandwidth of the detector or digitizer $[94,96]$. OFDR has been applied to measure temperature and strain with a centimeter-scale spatial resolution [97], and the measurement distance is typically up to hundreds of meters.

\subsection{Raman Scattering Based Sensing Technologies}

The intensity of Raman scattering is dependent on the fiber temperature, which provides the physical basis for the measurement of absolute temperature [98]. Based on Raman scattering, Raman optical time domain reflectometry (ROTDR) and Raman frequency time domain reflectometry (ROFDR) have been developed for temperature measurement. Due to the weak scattering intensity, the spatial resolution of ROTDR is typically limited to about $1 \mathrm{~m}$ with a measurement distance of $10 \mathrm{~km}$. Recently, a superconducting nanowire single-photon detector was developed and utilized to improve the spatial resolution of ROTDR to the order of $1 \mathrm{~cm}$ at $1550 \mathrm{~nm}$ wavelength [99]. This development potentially can facilitate wider applications of Raman scattering based distributed sensors for structural fire applications in the future; however, sampling times need to be significantly reduced to make this technology applicable in structural fire applications.

\subsection{Brillouin Scattering Based Sensing Technologies}

The distribution of Brillouin scattering spectrum was first measured through Brillouin optical time domain analysis (BOTDA) [100]. BOTDA measures backscattering signals in an optical fiber due to the combined effect of strain and temperature as a result of a forward-propagating (incipient) pulse pump light wave and a back-propagating continuous probe wave [18]. If the pump and probe waves are tuned to have time-varying frequency differences corresponding to the Brillouin frequency of optical fiber, the Brillouin gain as a function of position can be determined by the time-varying probe wave. The Brillouin frequency can be mapped along the optical fiber, which enables measurement of strain and temperature distributions [101,102]. Brillouin optical time domain reflectometry (BOTDR) has the advantage of single-ended measurement [103]. However, the spatial resolution is on the order of meters, which is mainly limited by the pulse width. While a narrow bandwidth pulse can lead to higher resolution, the bandwidth must be longer than the phonon relaxation time. It has been demonstrated that $28 \mathrm{~ns}$ is required to get the phonon fully stimulated, which corresponds to a $3 \mathrm{~m}$ spatial resolution. To resolve this problem, pulse pre-pump BOTDA (PPP-BOTDA) was proposed [104], which uses a pre-pump pulse that stimulates the phonon before a narrow bandwidth pulse arrives, achieving a $2 \mathrm{~cm}$ spatial resolution using a $0.2 \mathrm{~ns}$ short pulse. On the other hand, frequency domain distributed sensing technologies have been developed such as Brillouin optical frequency domain analysis (BOFDA) [105] and Brillouin optical correlation domain analysis (BOCDA) [106]. In a short distance (e.g., $\approx 10 \mathrm{~m}$ ), the spatial resolution can achieve $3 \mathrm{~cm}$ by BOFDA and $1 \mathrm{~cm}$ by BOCDA [107]. However, the spatial resolution can be up to $7 \mathrm{~cm}$ for a $1 \mathrm{~km}$ measurement distance [108].

\subsection{Structural Fire Applications}

The capability of measuring temperature distributions along the whole fiber length makes distributed fiber optic sensors well-suited for fire detection in structures such as tunnels [109-114]. Rayleigh OFDR was used to monitor temperature distribution for a nuclear reactor with a spatial resolution of $1 \mathrm{~cm}$ up to $850{ }^{\circ} \mathrm{C}$ [97]. ROTDR was operated at temperatures up to $1000{ }^{\circ} \mathrm{C}$ with 
a temperature uncertainty of less than $30^{\circ} \mathrm{C}$ [115]. BOTDA was investigated for measuring temperature distributions in an electric furnace at up to $1000{ }^{\circ} \mathrm{C}$ using a fused silica single mode fiber [116-120]. In addition to measuring temperature, Bao and Chen investigated the strain sensing performance of a distributed fiber optic sensor at temperatures up to $800^{\circ} \mathrm{C}$, and temperature dependency of the strain and temperature sensitivity coefficients was quantified using PPP-BOTDA [121]. Brillouin frequency was measured and converted into strain and temperature distributions along the optical fiber with temperature compensation [122-124]. Temperature compensation can be realized using an additional distributed fiber optic sensor free of strain effect for temperature measurement or using two different distributed sensing approaches with different temperature and strain sensitivities [18]. For example, Rayleigh OFDR and BOTDA have different temperature and strain sensitivities, thus temperature and strain can be solved for each point. The distributed fiber optic sensor was applied to measure the coefficient of thermal expansion of steel [121]. These studies demonstrated the feasibility of distributed fiber optic sensors for high temperature applications.

PPP-BOTDA was first applied in structural fire testing for measuring temperature and strain distributions in optical fibers installed on steel beams [67,125]. The distributed fiber optic sensors were installed along the top and bottom flanges of a hot-rolled S-shaped A36 mild steel beam exposed to the fire [125]. The steel beam was simply supported and subjected to a concentrated mechanical loading at the mid-span. Telecommunication-grade single-mode optical fibers were loosely passed through steel tubes attached on the steel beam for measuring temperature distributions, and a mechanism for scaling down the strain in the steel beam was used to design the strain sensor, as shown in Figure 11. The mechanism helps protect the optical fiber from fracture under significant deformation of the steel beam in a fire. For comparison, type-K thermocouples were used to measure temperatures, and EFPI sensors were also used to measure strains. The temperature sensor measured temperatures up to $1050{ }^{\circ} \mathrm{C}$. However, the strain sensors failed below $600{ }^{\circ} \mathrm{C}$, due to the increase of strain and degradation of the fused silica fiber at elevated temperatures [121]. Based on the measured temperature distributions over the beam, an enhanced thermomechanical analysis procedure was developed to predict the mechanical responses of steel beams in the fire [125].
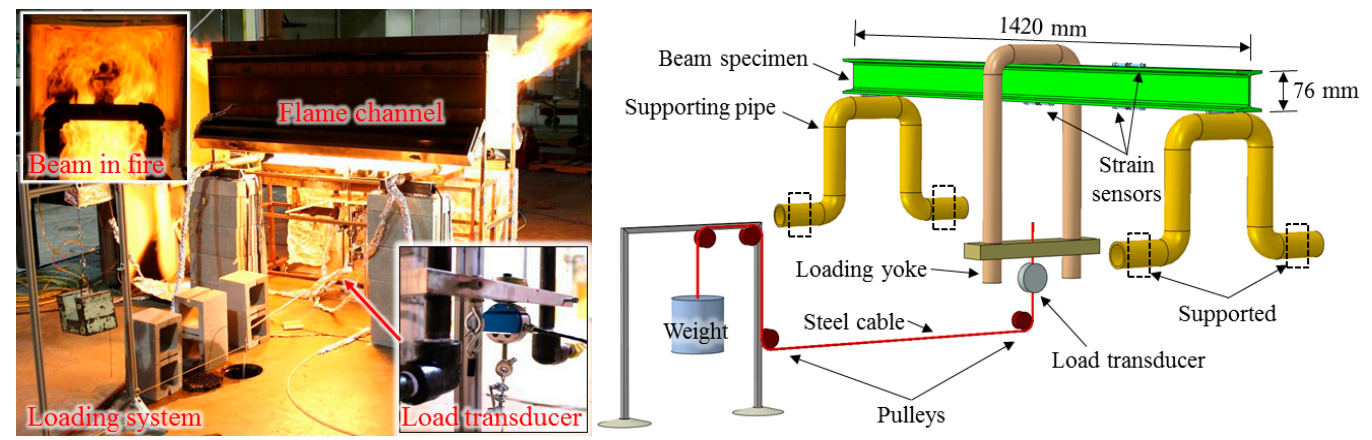

(a)
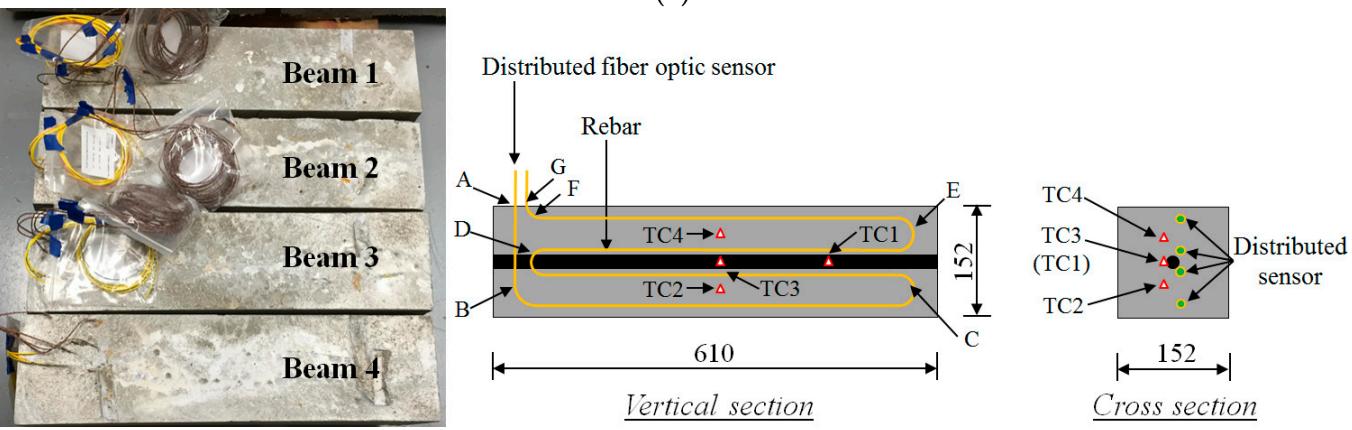

(b)

Figure 11. Applications of distributed fiber optic sensors in structural fire testing of: (a) Steel beam [125], and (b) reinforced concrete beam [126]. 
Distributed fiber optic sensors were embedded in reinforced concrete beams for condition assessment [126]. Before concrete casting, telecommunication-grade single-mode optical fibers were installed in the formwork. Type-K thermocouples were embedded in the beams to measure temperatures for comparison. After the concrete cured, they were subjected to open flames from a gas burner. The distributed sensor measured temperature distributions with a $2 \mathrm{~cm}$ spatial resolution in the beams based on the PPP-BOTDA. Concrete cracks were identified from the measured temperature distributions. The distributed fiber optic sensors failed after significant concrete spalling occurred due to fiber fracture.

Recently, a comparative study was conducted on measuring temperature distributions in a concrete container exposed to fire using different distributed sensing methods [127]. Fiber optic cables were attached on the surface of the container following a spiral path to map three-dimensional temperature profiles for the container. The cable had two polyimide coated optical fibers embedded inside a stainless-steel loose tube allowing fiber slipping. Temperature distribution along the optical fiber was measured using ROTDR, Rayleigh OFDR, tunable-wavelength coherent optical time domain reflectometry (TW-COTDR) based on Rayleigh scattering, PPP-BOTDA. For the ROTDR, the spatial resolution was $25 \mathrm{~cm}$; the measurement duration was $60 \mathrm{~s}$; the measurement distance was $100 \mathrm{~m}$, and the temperature accuracy was $0.11^{\circ} \mathrm{C}$. For the Rayleigh OFDR, the spatial resolution was $3 \mathrm{~cm}$, and the measurement distance was $70 \mathrm{~m}$. For the TW-COTDR and PPP-BOTDA, the spatial resolution was $5 \mathrm{~cm}$, and the measurement distance was $100 \mathrm{~m}$. For comparison, 250 type-K thermocouples were embedded inside the concrete; 15 reference sensors were fully collocated with the fiber optic cable. While the gas temperature inside the fire chamber reached $1000^{\circ} \mathrm{C}$, the temperature of the concrete container remained below $100{ }^{\circ} \mathrm{C}$. The discrepancy between the thermocouple and the distributed sensors was about $0.1^{\circ} \mathrm{C}$.

\section{Summary of Key Characteristics, Challenges, and Opportunities}

\subsection{Key Characteristics}

Table 1 summarizes the fiber optic sensors discussed in this paper and their key characteristics for measuring temperature and strain in structural fire applications. The values are based on the experience of the authors and data in the cited references; they are intended as general guidance. The listed upper temperatures may not be applicable in specific cases. The sensor length refers to the length of the sensing part of point sensors or the maximum sensing distance of distributed sensors. The operating distances, spatial resolutions, and measurement times are based on typical hardware and software and may change when different hardware or software is adopted. The sensor fabrication effort and technology stage are rated to give a relative sense of the technologies.

Table 1. Summary of high temperature fiber optic sensors.

\begin{tabular}{|c|c|c|c|c|c|c|c|c|}
\hline Sensor & Type & Measurand & $\begin{array}{c}\text { Upper } \\
\text { Temperature }\end{array}$ & $\begin{array}{l}\text { Sensor } \\
\text { Length }\end{array}$ & $\begin{array}{l}\text { Spatial } \\
\text { Resolution }\end{array}$ & $\begin{array}{l}\text { Measurement } \\
\text { Time }\end{array}$ & $\begin{array}{c}\text { Fabrication } \\
\text { Effort }\end{array}$ & $\begin{array}{l}\text { Technology } \\
\text { Stage }\end{array}$ \\
\hline Ordinary FBG & Point & $\mathrm{T}, \varepsilon$ & $400^{\circ} \mathrm{C}$ & $\approx 5 \mathrm{~mm}$ & - & $<1 \mathrm{~s}$ & Low & Mature \\
\hline RFBG * & Point & $\mathrm{T}^{* *}$ & $1295^{\circ} \mathrm{C}$ & $\approx 5 \mathrm{~mm}$ & - & $<1 \mathrm{~s}$ & High & Mature \\
\hline fs-FBG * & Point & $\mathrm{T}^{* *}$ & $1100{ }^{\circ} \mathrm{C}$ & $\approx 5 \mathrm{~mm}$ & - & $<1 \mathrm{~s}$ & High & Emerging \\
\hline Sapphire FBG & Point & $\mathrm{T}^{* *}$ & $1850^{\circ} \mathrm{C}$ & $\approx 5 \mathrm{~mm}$ & - & $<1 \mathrm{~s}$ & High & Emerging \\
\hline LPFG & Point & $\mathrm{T}, \varepsilon$ & $1200^{\circ} \mathrm{C}$ & $\approx 30 \mathrm{~mm}$ & - & $<1 \mathrm{~s}$ & Medium & Developing \\
\hline EFPI & Point & $\varepsilon$ & $1000^{\circ} \mathrm{C}$ & $\approx 5 \mathrm{~mm}$ & - & $<1 \mathrm{~s}$ & High & Developing \\
\hline IFPI & Point & $\mathrm{T}^{* *}$ & $1100^{\circ} \mathrm{C}$ & $\approx 5 \mathrm{~mm}$ & - & $<1 \mathrm{~s}$ & Medium & Emerging \\
\hline CCMI & Point & $\mathrm{T}^{* *}$ & $1200^{\circ} \mathrm{C}$ & $\approx 5 \mathrm{~mm}$ & - & $<1 \mathrm{~s}$ & Medium & Emerging \\
\hline Rayleigh OTDR & Distributed & $\mathrm{T}^{* *}$ & $\approx 1000{ }^{\circ} \mathrm{C}$ & $\approx 10 \mathrm{~km}$ & $\approx 1 \mathrm{~m}$ & $3 \mathrm{~min}$ & Low & Developing \\
\hline Rayleigh OFDR & Distributed & $\mathrm{T}^{* *}$ & $\approx 1000{ }^{\circ} \mathrm{C}$ & $\approx 0.1 \mathrm{~km}$ & $\approx 1 \mathrm{~mm}$ & $<1 \mathrm{~s}$ & Low & Developing \\
\hline Raman OTDR & Distributed & $\mathrm{T}^{* *}$ & $\approx 1000^{\circ} \mathrm{C}$ & $\approx 30 \mathrm{~km}$ & $\approx 10 \mathrm{~mm}$ & $\approx 60 \mathrm{~s}$ & Low & Developing \\
\hline Brillouin OTDA & Distributed & $\mathrm{T}, \varepsilon$ & $\approx 1200{ }^{\circ} \mathrm{C}$ & $\approx 100 \mathrm{~km}$ & $\approx 20 \mathrm{~mm}$ & $1 \mathrm{~s}-60 \mathrm{~s}$ & Low & Mature \\
\hline
\end{tabular}

${ }^{*}$ RFBG $=$ regenerated FBG. fs-FBG $=$ femtosecond laser fabricated FBG; ${ }^{* *}$ Although the sensors are sensitive to strain, to the author's knowledge they have not been used to measure strain in structure fires to date. 


\subsection{Challenges and Opportunities}

A primary challenge for fiber optic sensors in structural fire engineering is the lack of reliable, effective, and efficient packaging for the optical fiber for field deployment. The packaging here refers to the means and methods used to both protect the sensor and attach it to the structure. Proper packaging is critical for both point and distributed sensors. Mechanical damage or thermal degradation of the optical fiber may cause the sensor to fail prematurely. Soot and smoke can degrade the performed of interferometer sensors. For polymer-coated optical fibers, although the fused silica fiber retains its integrity after the polymer has burned, thermal degradation may be accelerated due to the absence of the protective coating [128]. In particular, for measurements of strain in materials, reliable and well-characterized means of coupling the fiber to the structure at high temperatures are lacking; in particular for distributed fiber optic sensors.

Point sensors have shown great promise in measuring high temperature and large strains. Although point sensors have the potential to form quasi-distributed sensors through multiplexing, further research is needed to verify the feasibility in structural fire performance. The IFPI and CCMI sensors have demonstrated promising high-temperature measurement performance in the laboratory and are relatively cost-effective to fabricate. However, their structural fire performance must be evaluated in the future. Distributed fiber optic sensors have the advantage of achieving a large number of sensing points at a low sensor cost, however, the data analyzers are currently expensive and require a high level of training.

More studies are needed for both point and distributed fiber optic sensors to characterize the uncertainty of the measurements of both strain and temperature in real structural fire conditions.

\subsection{Other Fiber Optic Sensors for Fire Safety Study}

In addition to the three types of fiber optic sensors discussed to measure temperature and strain in structural fire engineering, other fiber optic sensors have been used for fire detection by monitoring flame radiation [129-131], smoke [132], or gas [133-135] that serves as a precursor or indicator of combustion. Since different gases are produced in various types of fire, specific gas sensors must be appropriately selected. While the detection of smoke and gas indicates combustion, diffusion of smoke or gas from the combustion location to the sensors may take significant time.

Provided the availability of multiple types of sensors with different measurands, intelligent algorithms have been developed to prevent false fire alarms by combining the measurements from multiple types of sensors [136-138]. Furthermore, fiber optic-based fire systems can be integrated with structures' monitoring and control system $[139,140]$. It is envisioned that the advancement of artificial intelligence will greatly promote the advancement of sensor technology and transform the current applications of fiber optic sensors in fire safety.

\section{Conclusions}

Although fiber optic sensors have been widely applied for temperature and strain measurement in high-temperature applications, there remains limited knowledge of their performance in structural fire applications. This application typically has large, transient temperature variations, and challenging sensor installation conditions; typical of a building construction site. Synergized efforts of sensor designers and structural fire engineers are needed to further advance the technology. This paper reviews the sensing principles, fabrication, key characteristics, and recent applications of three classes of fiber optic sensors (i.e., grating, interferometer, and distributed sensors) in the context of structural fire engineering. The following conclusions are drawn:

- Fiber Bragg Grating (FBG) sensors that can measure temperature and strain at temperatures up to $1300{ }^{\circ} \mathrm{C}$ using fused silica fibers have been reported, however, sophisticated processes are required to achieve gratings stable at temperatures above $400^{\circ} \mathrm{C}$. 
- Long-Period Fiber Grating (LPFG) that are stable up to temperatures of $800{ }^{\circ} \mathrm{C}$ have been fabricated using cost-effective and simple processes. However, LPFGs have longer sensor lengths than FBGs, resulting in great spatial averaging, and are more sensitive to bending of the optical fiber and the refractive index of the environment. It has been the author's experience that this requires more attention to be paid to sensor installation and data interpretation.

- Fiber optic interferometer sensors have been developed to allow for the measurement of temperatures up to $1200{ }^{\circ} \mathrm{C}$ and strains up to about $10 \%$.

- Compared with grating sensors and interferometric sensors, which are point sensors, distributed fiber optic sensors allow for the measurements of distributions along optical fibers. The upper operating temperature of distributed fiber optic sensors has exceeded $1000{ }^{\circ} \mathrm{C}$ with a centimeter-scale spatial resolution for temperature measurements. Bonding of fibers to structural steel and concrete to reliably measure strains at temperatures greater than $100{ }^{\circ} \mathrm{C}$ remains a limiting factor for distributed fiber optic sensors.

- The required measurement times for the various techniques must be considered when selecting a technology for an application.

Author Contributions: Conceptualization, Y.B.; Methodology, Y.B., Y.H. and M.H.; Validation, Y.H., M.H. and G.C.; Formal Analysis, Y.B.; Investigation, Y.B.; Resources, Y.B.; Data Curation, Y.H.; Writing-Original Draft Preparation, Y.B.; Writing-Review \& Editing, M.H. and Y.H.; Visualization, Y.B.; Supervision, G.C.; Project Administration, M.H.; Funding Acquisition, G.C.

Funding: This work was funded by the National Institute of Standards and Technology (NIST) [grant number 70NANB13H183].

Conflicts of Interest: The authors declare no conflict of interest.

\section{References}

1. Kodur, V.; Dwaikat, M.; Fike, R. High-temperature properties of steel for fire resistance modeling of structures. J. Mater. Civ. Eng. 2010, 22, 423-434. [CrossRef]

2. Li, X.; Xu, H.; Meng, W.; Bao, Y. Tri-axial compressive properties of high-performance fiber-reinforced cementitious composites after exposure to high temperatures. Constr. Build. Mater. 2018, 190, 939-947. [CrossRef]

3. Li, X.; Bao, Y.; Wu, L.; Yan, Q.; Ma, H.; Chen, G.; Zhang, H. Thermal and mechanical properties of high-performance fiber-reinforced cementitious composites after exposure to high temperatures. Constr. Build. Mater. 2017, 157, 829-838. [CrossRef]

4. Li, X.; Bao, Y.; Xue, N.; Chen, G. Bond strength of steel bars embedded in high-performance fiber-reinforced cementitious composite before and after exposure to elevated temperatures. Fire Saf. J. 2017, 92, 98-106. [CrossRef]

5. Hunt, S.P.; Cutonilli, J.; Morgan Hurley, P.E. Evaluation of Enclosure Temperature Empirical Models; Society of Fire Protection Engineers: Bethesda, MD, USA, 2010.

6. Concrete Society. Assessment, Design and Repair of Fire-Damaged Concrete Structures; Concrete Society: Camberley, UK, 2008.

7. Luecke, W.E.; Banovic, S.W.; McColskey, J.D. High-Temperature Tensile Constitutive Data and Models for Structural Steels in Fire; Technical Note 1714; National Institute of Standards and Technology: Gaithersburg, MD, USA, 2011.

8. Li, G.; Zhang, C. Simple approach for calculating maximum temperature of insulated steel members in natural-fires. J. Constr. Steel Res. 2012, 71, 104-110. [CrossRef]

9. Jeffers, A.E.; Sotelino, E.D. An efficient fiber element approach for the thermo-structural simulation of non-uniformly heated frames. Fire Saf. J. 2012, 51, 18-26. [CrossRef]

10. Li, X.; Xu, Z.; Bao, Y.; Cong, Z. Post-fire seismic behavior of two-bay two-story frames with high-performance fiber-reinforced cementitious composite joints. Eng. Struct. 2019, 183, 150-159. [CrossRef]

11. Lönnermark, A.; Hedekvist, P.O.; Ingason, H. Gas temperature measurements using fibre Bragg grating during fire experiments in a tunnel. Fire Saf. J. 2008, 43, 119-126. [CrossRef] 
12. Busch, M.; Ecke, W.; Latka, I.; Fischer, D.; Willsch, R.; Bartelt, H. Inscription and characterization of Bragg gratings in single-crystal sapphire optical fibres for high-temperature sensor applications. Meas. Sci. Technol. 2009, 20, 115301. [CrossRef]

13. Elsmann, T.; Habisreuther, T.; Graf, A.; Rothhardt, M.; Bartelt, H. Inscription of first-order sapphire Bragg gratings using $400 \mathrm{~nm}$ femtosecond laser radiation. Opt. Express 2013, 21, 4591-4597. [CrossRef]

14. Li, H.N.; Li, D.S.; Song, G.B. Recent applications of fiber optic sensors to health monitoring in civil engineering. Eng. Struct. 2004, 26, 1647-1657. [CrossRef]

15. Udd, E.; Spillman, W.B., Jr. (Eds.) Fiber Optic Sensors: An Introduction for Engineers and Scientists; John Wiley \& Sons: Hoboken, NJ, USA, 2010.

16. Grattan, K.T.V.; Sun, T. Fiber optic sensor technology: An overview. Sens. Actuator A Phys. 2000, 82, 40-61. [CrossRef]

17. Krohn, D.A.; MacDougall, T.; Mendez, A. Fiber Optic Sensors: Fundamentals and Applications; SPIE Press: Bellingham, WA, USA, 2014.

18. Bao, X.; Chen, L. Recent progress in distributed fiber optic sensors. Sensors 2012, 12, 8601-8639. [CrossRef] [PubMed]

19. Kersey, A.D.; Berkoff, T.A.; Morey, W.W. Multiplexed fiber Bragg grating strain-sensor system with a fiber Fabry-Perot wavelength filter. Opt. Lett. 1993, 18, 1370-1372. [CrossRef] [PubMed]

20. Bhatia, V.; Vengsarkar, A.M. Optical fiber long-period grating sensors. Opt. Lett. 1996, 21, 692-694. [CrossRef] [PubMed]

21. Hill, K.O.; Meltz, G. Fiber Bragg grating technology fundamentals and overview. J. Lightw. Technol. 1997, 15, 1263-1276. [CrossRef]

22. Hill, K.O.; Malo, B.; Bilodeau, F.; Johnson, D.C.; Albert, J. Bragg gratings fabricated in monomode photosensitive optical fiber by UV exposure through a phase mask. Appl. Phys. Lett. 1993, 62, 1035-1037. [CrossRef]

23. Canning, J. Fibre gratings and devices for sensors and lasers. Laser Photonics Rev. 2008, 2, 275-289. [CrossRef]

24. Meltz, G.; Morey, W.W.; Glenn, W.H. Formation of Bragg gratings in optical fibers by a transverse holographic method. Opt. Lett. 1989, 14, 823-825. [CrossRef]

25. Archambault, J.L.; Reekie, L.; Russell, P.S.J. High reflectivity and narrow bandwidth fibre gratings written by single excimer pulse. Electron. Lett. 1993, 29, 28-29. [CrossRef]

26. Askins, C.G.; Putman, M.A.; Williams, G.M.; Friebele, E.J. Stepped wavelength optical fiber Bragg grating arrays fabricated in line on a draw tower. Opt. Lett. 1994, 19, 147-149. [CrossRef] [PubMed]

27. Fokine, M. Underlying mechanisms, applications, and limitations of chemical composition gratings in silica based fibers. J. Non-Cryst. Solids 2004, 349, 98-104. [CrossRef]

28. Bandyopadhyay, S.; Canning, J.; Stevenson, M.; Cook, K. Ultrahigh-temperature regenerated gratings in boron-codoped germanosilicate optical fiber using $193 \mathrm{~nm}$. Opt. Lett. 2008, 33, 1917-1919. [CrossRef] [PubMed]

29. Dutz, F.J.; Lindner, M.; Heinrich, A.; Seydel, C.G.; Bosselmann, T.; Koch, A.W.; Roths, J. Multipoint high temperature sensing with regenerated fiber Bragg gratings. In Fiber Optic Sensors and Applications XV; International Society for Optics and Photonics: Bellingham, WA, USA, 2018; Volume 10654, p. 1065407.

30. Zhang, B.; Kahrizi, M. High-temperature resistance fiber Bragg grating temperature sensor fabrication. IEEE Sens. J. 2007, 7, 586-591. [CrossRef]

31. Li, Y.; Yang, M.W.; Wang, D.N.; Lu, J.; Sun, T.; Grattan, K.T.V. Fiber Bragg gratings with enhanced thermal stability by residual stress relaxation. Opt. Express 2009, 17, 19785-19790. [CrossRef]

32. Canning, J.; Stevenson, M.; Bandyopadhyay, S.; Cook, K. Extreme silica optical fibre gratings. Sensors 2008, 8, 6448-6452. [CrossRef]

33. Bueno, A.; Torres, B.; Barrera, D.; Calderón, P.; Lloris, J.M.; López, M.J.; Sales, S. Fiber Bragg grating sensors embedded in concrete samples for a normalized fire test. In Proceedings of the 21st International Conference on Optical Fiber Sensors, Ottawa, ON, Canada, 15-19 May 2011; Volume 7753, p. 77538.

34. International Organization for Standardization. Fire Resistance Tests-Elements of Building Construction-Part 10: Specific Requirements to Determine the Contribution of Applied Fire Protection Materials to Structural Steel Elements; ISO 834-10:2014; International Organization for Standardization: Geneva, Switzerland, 2014.

35. Rinaudo, P.; Torres, B.; Paya-Zaforteza, I.; Calderón, P.A.; Sales, S. Evaluation of new regenerated fiber Bragg grating high-temperature sensors in an ISO834 fire test. Fire Saf. J. 2015, 71, 332-339. [CrossRef] 
36. Torres, B.; Payá-Zaforteza, I.; Calderón, P.A.; Sales, S. New fiber optic sensor for monitoring temperatures in concrete structures during fires. Sens. Actuator A Phys. 2017, 254, 116-125.

37. Martinez, A.; Dubov, M.; Khrushchev, I.; Bennion, I. Direct writing of fibre Bragg gratings by femtosecond laser. Electron. Lett. 2004, 40, 1170-1172. [CrossRef]

38. Mihailov, S.J.; Smelser, C.W.; Grobnic, D.; Walker, R.B.; Lu, P.; Ding, H.; Unruh, J. Bragg gratings written in all-SiO $\mathrm{S}_{2}$ and $\mathrm{Ge}$-doped core fibers with 800-nm femtosecond radiation and a phase mask. J. Lightw. Technol. 2004, 22, 94-100. [CrossRef]

39. Smelser, C.; Mihailov, S.; Grobnic, D. Formation of Type I-IR and Type II-IR gratings with an ultrafast IR laser and a phase mask. Opt. Express 2005, 13, 5377-5386. [CrossRef]

40. Grobnic, D.; Smelser, C.W.; Mihailov, S.J.; Walker, R.B. Long-term thermal stability tests at $1000{ }^{\circ} \mathrm{C}$ of silica fibre Bragg gratings made with ultrafast laser radiation. Meas. Sci. Technol. 2006, 17, 1009-1013. [CrossRef]

41. Li, Y.; Liao, C.R.; Wang, D.N.; Sun, T.; Grattan, K.T.V. Study of spectral and annealing properties of fiber Bragg gratings written in $\mathrm{H}_{2}$-free and $\mathrm{H}_{2}$-loaded fibers by use of femtosecond laser pulses. Opt. Express 2008, 16, 21239-21247. [CrossRef]

42. James, S.W.; Tatam, R.P. Optical fibre long-period grating sensors: Characteristics and application. Meas. Sci. Technol. 2003, 14, R49. [CrossRef]

43. Chen, Y.; Tang, F.; Bao, Y.; Chen, G.; Tang, Y. Fe-C coated long period fiber grating sensors for steel corrosion monitoring. Opt. Lett. 2016, 41, 344-346.

44. Davis, D.D.; Gaylord, T.K.; Glytsis, E.N.; Kosinski, S.G.; Mettler, S.C.; Vengsarkar, A.M. Long-period fibre grating fabrication with focused $\mathrm{CO}_{2}$ laser beams. Electron. Lett. 1998, 34, 302-303. [CrossRef]

45. Kondo, Y.; Nouchi, K.; Mitsuyu, T.; Watanabe, M.; Kazansky, P.; Hirao, K. Fabrication of long-period fibre gratings by focused irradiation of infra-red femtosecond laser pulses. Opt. Lett. 1999, 24, 646-648. [CrossRef]

46. Rego, G.; Okhotnikov, O.; Dianov, E.; Sulimov, V. High-temperature stability of long-period fibre gratings using an electric arc. J. Lightw. Technol. 2001, 19, 1574-1579. [CrossRef]

47. Kakarantzas, G.; Birks, T.A.; Russell, P.S. Structural long-period gratings in photonic crystal fibers. Opt. Lett. 2002, 27, 1013-1015. [CrossRef]

48. Hwang, I.K.; Yun, S.H.; Kim, B.Y. Long period fibre grating based upon periodic microbends. Opt. Lett. 1999, 24, 1263-1265. [CrossRef]

49. Kakarantzas, G.; Dimmick, T.E.; Birks, T.A.; Le Roux, R.; St. Russell, P.J. Miniature all-fibre devices based on $\mathrm{CO}_{2}$ microstructuring of tapered fibers. Opt. Lett. 2001, 26, 1137-1139. [CrossRef]

50. Dianov, E.M.; Karpov, V.I.; Grekov, M.V.; Golant, K.M.; Vasiliev, S.A.; Medvekov, O.I.; Khrapko, R.R. Thermo-induced long period fibre grating. IOOC-ECOC 1997, 2, 53-56.

51. Guan, B.O.; Tam, H.Y.; Ho, S.L.; Liu, S.Y.; Dong, X.Y. Growth of long-period gratings in $\mathrm{H}_{2}$-loaded fibre after 193 nm UV inscription. IEEE Photonics Technol. Lett. 2000, 12, 642-644. [CrossRef]

52. Kim, C.S.; Han, Y.; Lee, BH.; Han, W.T.; Paek, U.C.; Chung, Y. Induction of the refractive index change in B-doped optical fibers through relaxation of the mechanical stress. Opt. Commun. 2000, 185, 337-342. [CrossRef]

53. Humbert, G.; Malki, A. Electric-arc-induced gratings in non-hydrogenated fibres: Fabrication and high-temperature characterizations. J. Opt. A Pure Appl. Opt. 2002, 4, 194-198. [CrossRef]

54. Huang, Y.; Zhou, Z.; Zhang, Y.; Chen, G.; Xiao, H. A temperature self-compensated LPFG sensor for large strain measurements at high temperature. IEEE Tract. Instrum. Meas. 2010, 59, 2997-3004. [CrossRef]

55. Huang, Y.; Chen, G.; Xiao, H.; Zhang, Y.; Zhou, Z. A quasi-distributed optical fiber sensor network for large strain and high temperature measurement of structures. Proc. SPIE 2011, 7983, 1-12.

56. Huang, Y.; Fang, X.; Bevans, W.J.; Zhou, Z.; Xiao, H.; Chen, G. Large-strain optical fiber sensing and real-time FEM updating of steel structures under the high temperature effect. Smart Mater. Struct. 2013, 22, 015016. [CrossRef]

57. Rao, Y.J. Recent progress in fiber-optic extrinsic Fabry-Perot interferometric sensors. Opt. Fiber Technol. 2006, 12, 227-237. [CrossRef]

58. Lipson, S.G.; Lipson, H.; Tannhauser, D.S. Optical Physics, 3rd ed.; Cambridge University Press: London, UK, 1995; ISBN 0-521-06926-2.

59. Lee, B.H.; Kim, Y.H.; Park, K.S.; Eom, J.B.; Kim, M.J.; Rho, B.S.; Choi, H.Y. Interferometric fiber optic sensors. Sensors 2012, 12, 2467-2486. [CrossRef] 
60. Lee, C.E.; Taylor, H.F. Interferometric sensors using internal fiber mirrors. Electron. Lett. 1988, $24,193-194$. [CrossRef]

61. Mathew, J.; Schneller, O.; Polyzos, D.; Havermann, D.; Carter, R.M.; MacPherson, W.N.; Hand, D.P.; Maier, R.R. In-fiber Fabry-Perot cavity sensor for high-temperature applications. J. Lightw. Technol. 2015, 33, 2419-2425. [CrossRef]

62. Wei, T.; Han, Y.K.; Li, Y.J.; Tsai, H.L.; Xiao, H. Temperature-insensitive miniaturized fiber inline Fabry-Perot interferometer for highly sensitive refractive index measurement. Opt. Express 2008, 16, 5764-5769. [CrossRef]

63. Duan, D.W.; Rao, Y.J.; Wen, W.P.; Yao, J.; Wu, D.; Xu, L.C.; Zhu, T. In-line all-fibre Fabry-Perot interferometer high temperature sensor formed by large lateral offset splicing. Electron. Lett. 2011, 47, 1702-1703.

64. Machavaram, V.R.; Badcock, R.A.; Fernando, G.F. Fabrication of intrinsic fibre Fabry-Perot sensors in silica fibres using hydrofluoric acid etching. Sens. Actuator A Phys. 2007, 138, 248-260. [CrossRef]

65. Tafulo, P.A.; Jorge, P.A.S.; Santos, J.L.; Frazão, O. Fabry-Pérot cavities based on chemical etching for high temperature and strain measurement. Opt. Commun. 2012, 285, 1159-1162. [CrossRef]

66. Duan, D.W.; Rao, Y.J.; Hou, Y.S.; Zhu, T. Microbubble based fiber-optic Fabry-Perot interferometer formed by fusion splicing single-mode fibers for strain measurement. Appl. Opt. 2012, 51, 1033-1036. [CrossRef]

67. Bao, Y.; Chen, Y.; Hoehler, M.S.; Smith, C.M.; Bundy, M.; Chen, G. Temperature and strain measurements with fiber optic sensors for steel beams subjected to fire. In Proceedings of the 9 th International Conference on Structures in Fire, Princeton, NJ, USA, 8-10 June 2016.

68. Claus, R.O.; Gunther, M.F.; Wang, A.; Murphy, K.A. Extrinsic Fabry-Perot sensor for strain and crack opening displacement measurements from - 200 to 900 degrees C. Smart Mater. Struct. 1992, 1, 237. [CrossRef]

69. Zhu, T.; Ke, T.; Rao, Y.J.; Chiang, K.S. Fabry-Perot optical fiber tip sensor for high temperature measurement. Opt. Commun. 2010, 283, 3683-3685. [CrossRef]

70. Li, E.; Peng, G.D.; Ding, X. High spatial resolution fiber-optic Fizeau interferometric strain sensor based on an in-fiber spherical microcavity. Appl. Phys. Lett. 2008, 92, 101117-101119. [CrossRef]

71. Villatoro, J.; Finazzi, V.; Coviello, G.; Pruneri, V. Photonic-crystal-fiber-enabled micro-Fabry-Perot interferometer. Opt. Lett. 2009, 34, 2441-2443. [CrossRef]

72. Deng, M.; Tang, C.P.; Zhu, T.; Rao, Y.J. PCF-based Fabry-Perot interferometric sensor for strain measurement at high temperatures. IEEE Photonics Technol. Lett. 2011, 23, 700-702. [CrossRef]

73. Zhu, T.; Wu, D.; Liu, M.; Duan, D. In-line fiber optic interferometric sensors in single-mode fibers. Sensors 2012, 12, 10430-10449. [CrossRef]

74. Wang, J.; Dong, B.; Lally, E.; Gong, J.; Han, M.; Wang, A. Multiplexed high temperature sensing with sapphire fiber air gap-based extrinsic Fabry-Perot interferometers. Opt. Lett. 2010, 35, 619-621. [CrossRef]

75. Huang, C.; Lee, D.; Dai, J.; Xie, W.; Yang, M. Fabrication of high-temperature temperature sensor based on dielectric multilayer film on Sapphire fiber tip. Sens. Actuator A Phys. 2015, 232, 99-102. [CrossRef]

76. Allsop, T.; Reeves, R.; Webb, D.J.; Bennion, I.; Neal, R. A high sensitivity refractometer based upon a long period grating Mach-Zehnder interferometer. Rev. Sci. Instrum. 2002, 73, 1702-1705. [CrossRef]

77. Villatoro, J.; Monzón-Hernández, D. Low-cost optical fiber refractive-index sensor based on core diameter mismatch. J. Lightw. Technol. 2006, 24, 1409-1413. [CrossRef]

78. Ngyuen, L.V.; Hwang, D.; Moon, S.; Moon, D.S.; Chung, Y.J. High temperature fiber sensor with high sensitivity based on core diameter mismatch. Opt. Express 2008, 16, 11369-11375. [CrossRef]

79. Zhu, J.J.; Zhang, A.P.; Xia, T.H.; He, S.; Xue, W. Fiber-optic high-temperature sensor based on thin-core fiber modal interferometer. IEEE Sens. J. 2010, 10, 1415-1418.

80. Choi, H.Y.; Kim, M.J.; Lee, B.H. All-fiber Mach-Zehnder type interferometers formed in photonic crystal fiber. Opt. Express 2007, 15, 5711-5720. [CrossRef]

81. Jiang, L.; Yang, J.; Wang, S.; Li, B.; Wang, M. Fiber Mach-Zehnder interferometer based on microcavities for high-temperature sensing with high sensitivity. Opt. Lett. 2011, 36, 3753-3755. [CrossRef]

82. Wang, Y.; Li, Y.; Liao, C.L.; Wang, D.N.; Liu, S.J.; Lu, P.X. Fiber in-line high-temperature sensing using miniaturized fiber in-line Mach-Zehnder interferometer. J. Opt. Soc. Am. B 2010, 27, 370-374. [CrossRef]

83. Monzón-Hernández, D.; Minkovich, V.P.; Villatoro, J. High-temperature sensing with tapers made of microstructured optical fiber. IEEE Photonics Technol. Lett. 2006, 18, 511-513. [CrossRef]

84. Lu, P.; Men, L.; Sooley, K.; Chen, Q. Tapered fiber Mach-Zehnder interferometer for simultaneous measurement of refractive index and temperature. Appl. Phys. Lett. 2009, 94, 131110. [CrossRef] 
85. Swart, P.L. Long-period grating Michelson refractometric sensor. Meas. Sci. Technol. 2004, 15, 1576-1580. [CrossRef]

86. Tian, Z.B.; Yam, S.S.H.; Loock, H.P. Single mode fiber refractive index sensor based on core-offset attenuators. IEEE Photonics Technol. Lett. 2008, 20, 1387-1389. [CrossRef]

87. Tian, Z.B.; Yam, S.S.H.; Loock, H.P. Refractive index sensor based on an abrupt taper Michelson interferometer in a single-mode fiber. Opt. Lett. 2008, 33, 1105-1107. [CrossRef]

88. Li, E.; Wang, X.; Zhang, C. Fiber-optic temperature sensor based on interference of selective higher-order modes. Appl. Phys. Lett. 2006, 89, 091119. [CrossRef]

89. Xu, L.; Jiang, L.; Wang, S.; Li, B.; Lu, Y. High-temperature sensor based on an abrupt-taper Michelson interferometer in single-mode fiber. Appl. Opt. 2013, 52, 2038-2041. [CrossRef]

90. Bao, X.; Chen, L. Recent progress in Brillouin scattering based fiber sensors. Sensors 2011, 11, $4152-4187$. [CrossRef]

91. Takada, K.; Himeno, A.; Yukimatsu, K. Phase-noise and shot-noise limited operations of low coherence optical time domain reflectometry. Appl. Phys. Lett. 1991, 59, 2483-2485. [CrossRef]

92. Yilmaz, G.; Karlik, S.E. A distributed optical fiber sensor for temperature detection in power cables. Sens. Actuator A Phys. 2006, 125, 148-155. [CrossRef]

93. Pinto, N.M.P.; Frazao, O.; Baptista, J.M.; Santos, J.L. Quasi-distributed displacement sensor for structural monitoring using a commercial OTDR. Opt. Laser Eng. 2006, 44, 771-778. [CrossRef]

94. Soller, B.J.; Gifford, D.K.; Wolfe, M.S.; Froggatt, M.E. High resolution optical frequency domain reflectometry for characterization of components and assemblies. Opt. Express 2005, 13, 666-674. [CrossRef]

95. Wan, K.T.; Leung, C. Applications of a distributed fiber optic crack sensor for concrete structures. Actuator A Phys. 2007, 135, 458-464. [CrossRef]

96. Kingsley, S.A.; Davies, D.E.N. OFDR diagnostics for fibre and integrated-optic systems. Electron. Lett. 1985, 21, 434-435. [CrossRef]

97. Sang, A.K.; Froggatt, M.E.; Gifford, D.K.; Kreger, S.T.; Dickerson, B.D. One centimeter spatial resolution temperature measurement in a nuclear reactor using Rayleigh scatter in optical fiber. IEEE Sens. J. 2008, 8 , 1375-1380. [CrossRef]

98. Dakin, J.P.; Pratt, D.J.; Bibby, G.W.; Ross, J.N. Distributed optical fiber Raman temperature sensor using a semiconductor light source and detector. Electron. Lett. 1985, 21, 569-570. [CrossRef]

99. Tanner, M.G.; Dyer, S.D.; Baek, B.; Hadfield, R.H.; Woo Nam, S. High-resolution single-mode fiber-optic distributed Raman sensor for absolute temperature measurement using superconducting nanowire single-photon detectors. Appl. Phys. Lett. 2011, 99, 201110. [CrossRef]

100. Horiguchi, T.; Kurashima, T.; Tateda, M. Tensile strain dependence of Brillouin frequency shift in silica optical fibers. IEEE Photonics Technol. Lett. 1989, 1, 107-108. [CrossRef]

101. Brown, G.A.; Hartog, A.H. Optical fiber sensors in upstream oil and gas. J. Pet. Technol. 2002, 54, $63-65$. [CrossRef]

102. Belal, M.; Cho, Y.T.; Ibsen, M.; Newson, T.P. A temperature-compensated high spatial resolution distributed strain sensor. Meas. Sci. Technol. 2010, 21, 015204. [CrossRef]

103. Shimizu, K.; Horiguchi, T.; Koyamada, Y.; Kurashima, T. Coherenet self-heterodyne detection of spontaneously Brillouin-scattered light waves in a single-mode fiber. Opt. Lett. 1993, 18, 185-187. [CrossRef]

104. Kishida, K.; Li, C.H. Pulse pre-pump-BOTDA technology for new generation of distributed strain measuring system. In Proceedings of the 2nd Structural Health Monitoring of Intelligent Infrastructure, Shenzhen, China, 16-18 November 2006; pp. 471-477.

105. Garus, D.; Golgolla, T.; Krebber, K.; Schliep, F. Brillouin optical frequency-domain analysis for distributed temperature and strain measurements. J. Lightw. Technol. 1997, 15, 654-662. [CrossRef]

106. Hotate, K.; Hasegawa, T. Measurement of Brillouin gain spectrum distribution along an optical fiber with a high spatial resolution using a correlation-based technique-Proposal, experiment and simulation. IEICE Trans. Electron. 2000, E83-C, 405-411.

107. Hotate, K.; Tanaka, M. Distributed fiber Brillouin strain sensing with $1 \mathrm{~cm}$ spatial resolution by correlation-based continuous-wave Technique. IEEE Photonics Technol. Lett. 2002, 14, 179-181. [CrossRef]

108. Hotate, K. Brillouin scattering accompanied by acoustic grating in an optical fiber and applications in fiber distributed sensing. Proc. SPIE 2011, 7753, 7-10. 
109. Meacham, B.J. International developments in fire sensor technology. J. Fire Prot. Eng. 1994, 6, 89-98. [CrossRef]

110. Li, W.; Ho, S.C.M.; Song, G. Corrosion detection of steel reinforced concrete using combined carbon fiber and fiber Bragg grating active thermal probe. Smart Mater. Struct. 2016, 25, 045017. [CrossRef]

111. Wang, A.; Liu, W.; Li, X.; Yue, C.; Wang, Y.; Wang, Q.; Cai, X. Distributed optical fiber temperature detecting and alarm system. In Proceedings of the 12th International Conference on Automatic Fire Detection, Gaithersburg, MD, USA, 25-28 March 2001.

112. Liu, Z.G.; Ferrier, G.; Bao, X.; Zeng, X.; Yu, Q.; Kim, A.K. Brillouin scattering based distributed fiber optic temperature sensing for fire detection. In Proceedings of the 7th International Symposium on Fire Safety Conference, Worcester, MA, USA, 16-21 June 2002.

113. Liu, Z.; Kim, A.K. Review of recent developments in fire detection technologies. J. Fire Prot. Eng. 2003, 13, 129-151. [CrossRef]

114. Glombitza, U.; Hoff, H. Fibre optic radar system for fire detection in cable trays. In Proceedings of the 13 th International Conference on Automatic Fire Detection, Duisberg, Germany, 14-16 September 2004.

115. Zhang, Z.; Guo, N.; Yu, X.; Wang, J.; Wu, X. Distributed fiber optics Raman high temperature $\left(1000{ }^{\circ} \mathrm{C}\right)$ measurement networks. Proc. SPIE 2001, 4603, 116.

116. Wang, J. Distributed Pressure and Temperature Sensing Based on Stimulated Brillouin Scattering. Master's Thesis, Virginia Polytechnic Institute and State University, Blacksburg, VA, USA, 2013.

117. Fellay, A. Extreme Temperature Sensing Using Brillouin Scattering in Optical Fibers. Ph.D. Thesis, Swiss Federal Institute of Technology Lausanne, Lausanne, Switzerland, 2003.

118. Li, Y.; Zhang, F.; Yoshino, T. Wide-range temperature dependence of Brillouin shift in a dispersion-shifted fiber and its annealing effect. J. Lightw. Technol. 2003, 21, 1663-1667.

119. Bao, Y.; Chen, G. Fully-distributed fiber optic sensor for strain measurement at high temperature. In Proceedings of the 10th International Workshop on Structural Health Monitoring, Stanford, CA, USA, 1-3 September 2015.

120. Bao, Y.; Chen, G. High temperature measurement with Brillouin optical time domain analysis. Opt. Lett. 2016, 41, 3177-3180. [CrossRef]

121. Bao, Y.; Chen, G. Temperature-dependent strain and temperature sensitivities of fused silica single mode fiber sensors. Meas. Sci. Technol. 2016, 27, 65101-65111. [CrossRef]

122. Bao, Y.; Meng, W.; Chen, Y.; Chen, G.; Khayat, K.H. Measuring mortar shrinkage and cracking by pulse pre-pump Brillouin optical time domain analysis with a single optical fiber. Mater. Lett. 2015, 145, 344-346. [CrossRef]

123. Bao, Y.; Chen, G. Strain distribution and crack detection in thin unbonded concrete pavement overlays with fully distributed fiber optic sensors. Opt. Eng. 2016, 55, 011008. [CrossRef]

124. Bao, Y.; Valipour, M.; Meng, W.; Khayat, K.H.; Chen, G. Distributed fiber optic sensor-enhanced detection and prediction of shrinkage-induced delamination of ultra-high-performance concrete bonded over an existing concrete substrate. Smart Mater. Struct. 2017, 26, 085009. [CrossRef]

125. Bao, Y.; Chen, Y.; Hoehler, M.S.; Smith, C.M.; Bundy, M.; Chen, G. Experimental analysis of steel beams subjected to fire enhanced by Brillouin scattering-based fiber optic sensor data. J. Struct. Eng. 2017, 143, 04016143. [CrossRef]

126. Bao, Y.; Hoehler, M.S.; Smith, C.M.; Bundy, M.; Chen, G. Temperature measurement and damage detection in concrete beams exposed to fire using PPP-BOTDA based fiber optic sensors. Smart Mater. Struct. 2017, 26, 105034. [CrossRef]

127. Delepine-Lesoille, S.; Planes, I.; Landolt, M.; Hermand, G.; Perrochon, O. Compared performances of Rayleigh, Raman, and Brillouin distributed temperature measurements during concrete container fire test. In Proceedings of the 25th International Conference on Optical Fiber Sensors, Jeju, Korea, 24-28 April 2017; Volume 10323, p. 103236.

128. Wysokiński, K.; Stańczyk, T.; Gibała, K.; Tenderenda, T.; Ziołowicz, A.; Słowikowski, M.; Broczkowska, M.; Nasiłowski, T. New methods of enhancing the thermal durability of silica optical fibers. Materials 2014, 7, 6947-6964. [CrossRef]

129. Garcia-Pichel, F. A scalar irradiance fiber-optic microprobe for the measurement of ultraviolet radiation at high spatial resolution. Photochem. Photobiol. 1995, 61, 248-254. [CrossRef] 
130. Zheng, Z.; Tong, X.; Wang, H.; Zhang, C.; Deng, C.; He, W. Research on sapphire-based optical fiber deep ultraviolet detection system working at high temperatures. Opt. Fiber Technol. 2019, 47, 88-92. [CrossRef]

131. Dai, X.; Liu, X.; Liu, L.; Zhu, B.; Fang, Z. A novel image-guided FT-IR sensor using chalcogenide glass optical fibers for the detection of combustion gases. Sens. Actuators B Chem. 2015, 220, 414-419. [CrossRef]

132. Brenci, M.; Guzzi, D.; Mencaglia, A.; Mignani, A.G. Fibre-optic smoke sensor. Sens. Actuators B Chem. 1992, 7, 780-783. [CrossRef]

133. Li, M.; Dubaniewicz, T.; Dougherty, H.; Addis, J. Evaluation of fiber optic methane sensor using a smoke chamber. Int. J. Min. Sci. Technol. 2018, 28, 969-974. [CrossRef]

134. Liu, T. Fibre optic sensors for coal mine hazard detection. In Handbook of Optical Fibers; Springer: New York, NY, USA, 2018; pp. 1-27.

135. Gong, Z.; Chen, K.; Yang, Y.; Zhou, X.; Yu, Q. Photoacoustic spectroscopy based multi-gas detection using high-sensitivity fiber-optic low-frequency acoustic sensor. Sens. Actuators B Chem. 2018, 260, 357-363. [CrossRef]

136. Meacham, B.J. The use of artificial intelligence techniques for signal discrimination in fire detection systems. J. Fire Prot. Eng. 1994, 6, 125-136. [CrossRef]

137. Arrue, B.C.; Ollero, A.; De Dios, J.M. An intelligent system for false alarm reduction in infrared forest-fire detection. IEEE Intell. Syst. Appl. 2000, 15, 64-73. [CrossRef]

138. Li, W.; Xu, C.; Ho, S.C.M.; Wang, B.; Song, G. Monitoring concrete deterioration due to reinforcement corrosion by integrating acoustic emission and FBG strain measurements. Sensors 2017, 17, 657. [CrossRef]

139. Ennals, B. Integrated systems-An evolution in building control. Fire Saf. Eng. 1999, 6, 10-12.

140. Sharples, S.; Callaghan, V.; Clarke, G. A multi-agent architecture for intelligent building sensing and control. Sens. Rev. 1999, 19, 135-140. [CrossRef]

(C) 2019 by the authors. Licensee MDPI, Basel, Switzerland. This article is an open access article distributed under the terms and conditions of the Creative Commons Attribution (CC BY) license (http:/ / creativecommons.org/licenses/by/4.0/). 